OPEN ACCESS

Edited by:

Zafar Said

University of Sharjah, United Arab

Emirates

Reviewed by:

Hyun-Seok Cho,

Korea Institute of Energy Research,

South Korea

Asif Mahmood,

The University of Sydney, Australia

${ }^{*}$ Correspondence:

Gowhar A. Naikoo

gahmed@du.edu.om

Mona Z. Pedram

m.zpedram@kntu.ac.ir

Mashallah Rezakazemi rezakazemi@shahroodut.ac.ir

Specialty section: This article was submitted to Electrochemistry,

a section of the journal

Frontiers in Chemistry

Received: 05 July 2021 Accepted: 06 October 2021 Published: 25 October 2021

Citation:

Naikoo GA, Arshad F, Hassan U,

Tabook MA, Pedram MZ,

Mustaqeem M, Tabassum $H$ Ahmed W and Rezakazemi M (2021) Thermocatalytic Hydrogen Production Through Decomposition of Methane-

A Review.

Front. Chem. 9:736801. doi: 10.3389/fchem.2021.736801

\section{Thermocatalytic Hydrogen Production Through Decomposition of Methane-A Review}

\author{
Gowhar A. Naikoo ${ }^{*}$, Fareeha Arshad ${ }^{2}$, Israr U. Hassan ${ }^{3}$, Musallam A. Tabook ${ }^{1}$, \\ Mona Z. Pedram ${ }^{4 *}$, Mujahid Mustaqeem ${ }^{5,6}$, Hassina Tabassum ${ }^{7}$, Waqar Ahmed ${ }^{8}$ and \\ Mashallah Rezakazemi ${ }^{8 *}$ \\ ${ }^{1}$ Department of Mathematics and Sciences, College of Arts and Applied Sciences, Dhofar University, Salalah, Oman, \\ ${ }^{2}$ Department of Biochemistry, Aligarh Muslim University, Aligarh, India, ${ }^{3}$ College of Engineering, Dhofar University, Salalah, Oman, \\ ${ }^{4}$ Mechanical Engineering-Energy Division, K. N. Toosi University of Technology, Tehran, Iran, ${ }^{5}$ Institute of Physics, Academia \\ Sinica, Taipei, Taiwan, ${ }^{6}$ Department of Chemistry, National Taiwan University, Taipei, Taiwan, ${ }^{7}$ Department of Chemical and \\ Biological Engineering, State University of New York at Buffalo, Buffalo, NY, United States, ${ }^{8}$ School of Mathematics and Physics, \\ College of Science, University of Lincoln, Lincoln, United Kingdom, ${ }^{9}$ Faculty of Chemical and Materials Engineering, Shahrood \\ University of Technology, Shahrood, Iran
}

Consumption of fossil fuels, especially in transport and energy-dependent sectors, has led to large greenhouse gas production. Hydrogen is an exciting energy source that can serve our energy purposes and decrease toxic waste production. Decomposition of methane yields hydrogen devoid of $\mathrm{CO}_{x}$ components, thereby aiding as an eco-friendly approach towards large-scale hydrogen production. This review article is focused on hydrogen production through thermocatalytic methane decomposition (TMD) for hydrogen production. The thermodynamics of this approach has been highlighted. Various methods of hydrogen production from fossil fuels and renewable resources were discussed. Methods including steam methane reforming, partial oxidation of methane, auto thermal reforming, direct biomass gasification, thermal water splitting, methane pyrolysis, aqueous reforming, and coal gasification have been reported in this article. A detailed overview of the different types of catalysts available, the reasons behind their deactivation, and their possible regeneration methods were discussed. Finally, we presented the challenges and future perspectives for hydrogen production via TMD. This review concluded that among all catalysts, nickel, ruthenium and platinum-based catalysts show the highest activity and catalytic efficiency and gave carbon-free hydrogen products during the TMD process. However, their rapid deactivation at high temperatures still needs the attention of the scientific community.

Keywords: hydrogen production, thermocatalytic methane decomposition, energy, catalysts, catalytic regeneration

Abbreviations: TMD, Thermo catalytic methane decomposition; Kmf, Threshold constant; SMR, Steam methane reforming; WGS, Water-gas shift reaction; POM, Partial Oxidation of Methane; ATR, Autothermal Reforming; DBG, Direct Biomass Gasification; TWS, Thermochemical Water Splitting; MP, Methane pyrolysis; CSS, CO2 capture and storage; APR, Aqueous Phase Reforming; CG, Coal Gasification. 


\section{INTRODUCTION}

Hydrogen $\left(\mathrm{H}_{2}\right)$ is one of the fundamental energy storage elements that are found in most chemical compounds including water and hydrocarbons. The future of world energy is dependent on hydrogen and therefore, the term "hydrogen economy" was coined that points out that highly pure hydrogen will have to be produced to sustain the hydrogen economy (Bockris, 2013; Eljack and Kazi, 2021). The worldwide production of hydrogen is $\sim 70$ million tons per year and is majorly produced from coal and gas. According to Energy Information Administration, about 7\% of natural gas is responsible for hydrogen production (Hydrogen Council, 2017). However, a very minute amount ( 6\%) of the hydrogen produced satiates the demand of pure hydrogen (Bockris, 2013; Eljack and Kazi, 2021). Hydrogen being a cleaner source of energy will replace the traditional fuel sources and help conserve the environment better. For hydrogen production, fossil fuels are the primary source owing to their inexpensive availability, easy access, and simple apparatus requirements (El-Shafie et al., 2019). However, their ability to cause environmental pollution is a major concern. Various methods have been explored for the production of hydrogen however, the steam reforming and coal gasification (Srilatha et al., 2017) methods have exhibited the dominance because of their exciting results. Depending upon the feedstock used, different pathways are adopted to produce concentrated hydrogen (Ghavam et al., 2021). Hydrogen is also derived from renewable sources like the naturally available wind and sun (Carroquino et al., 2019).
Hydrogen is also produced using elements like uranium among others (Chen et al., 2019a). Thus the different methods used in hydrogen production give varying amounts of hydrogen and in turn varying amounts of byproducts. For instance, hydrogen produced via fossil fuels accounts for 830 million tons of annual carbon dioxide that is about $\sim 2 \%$ of carbon dioxide emission worldwide (Baharuddin et al., 2021; Singla et al., 2021). As per the International Energy Agency, over 0.36 million tons of hydrogen produced was of low carbon in 2019 (Karaca and Dincer, 2020). This means that clean hydrogen production is about $0.52 \%$ of hydrogen produced worldwide and at this rate, 7.92 million tons of low carbon hydrogen will be produced yearly by 2030 (Karaca and Dincer, 2020). In order to decarbonize transport sector, Japan has formulated a hydrogen plan in 2014. This is to reduce the dependence on fossil fuels and decrease the resultant greenhouse emissions (Bockris, 2013; Eljack and Kazi, 2021) as shown in Figure 1.

Even pathways like hydrogen production via splitting of water using electricity have gained a widespread attraction among the scientific community (Figure 2) (Wang et al., 2021a). Renewable resources or non-renewable resources are used as feedstock during the electricity driven water splitting (Rozzi et al., 2020). During this reaction, there are two major half-cell reactions taking place: one in which reduction of water occurs at the cathode end to give hydrogen and at the other end oxygen evolution reaction occurs that gives oxygen as the product (Wang et al., 2021a). This reaction occurs in the presence of catalysts like metal based or non-metal based electrocatalysts

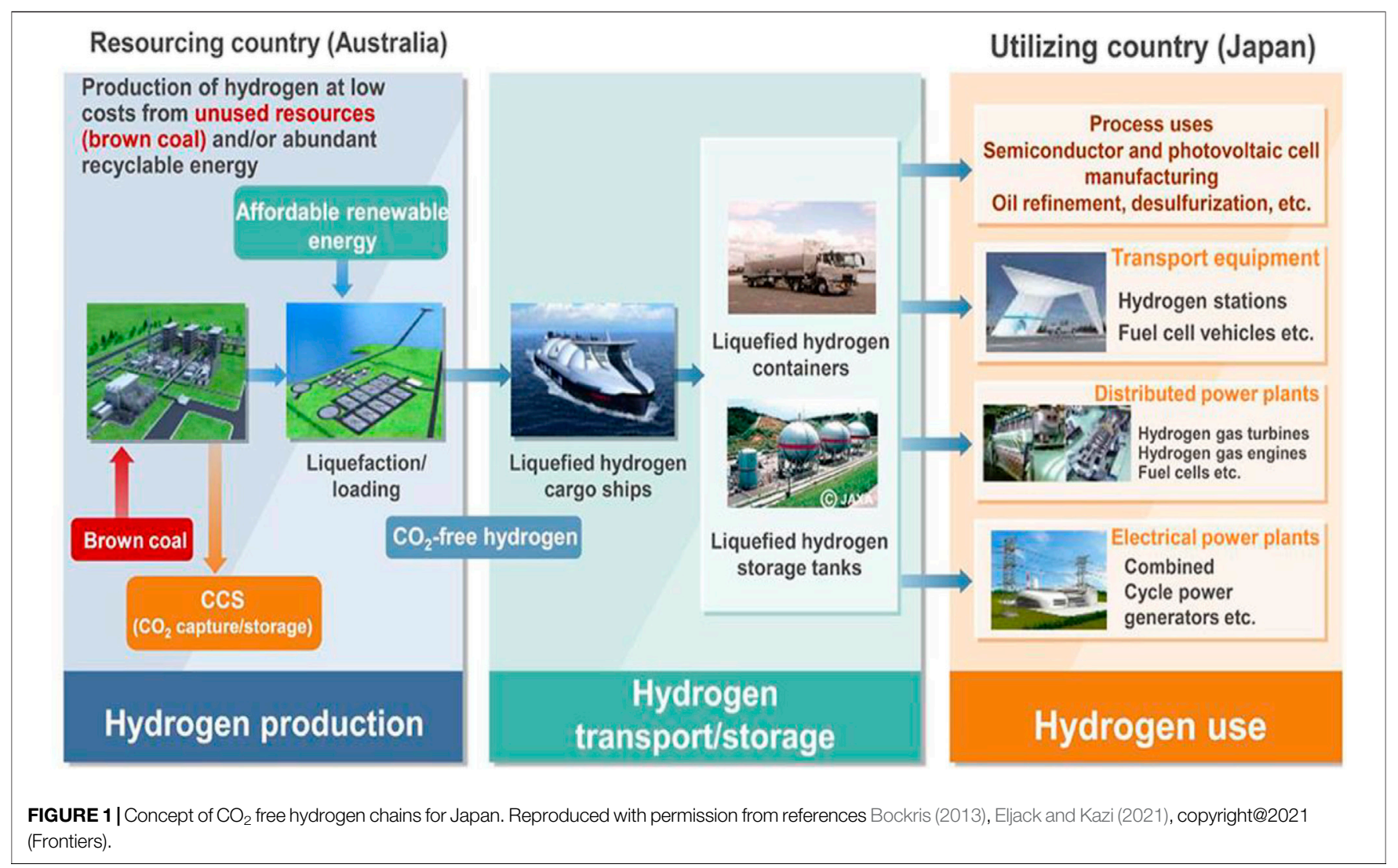


A

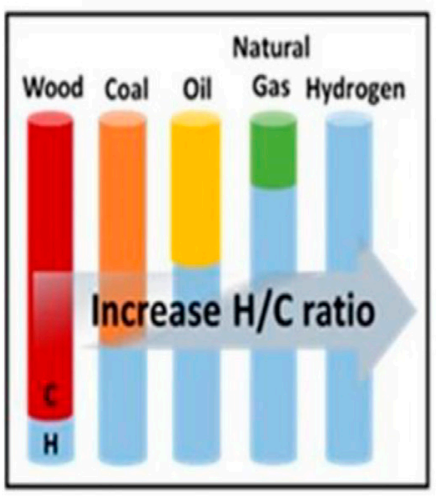

B

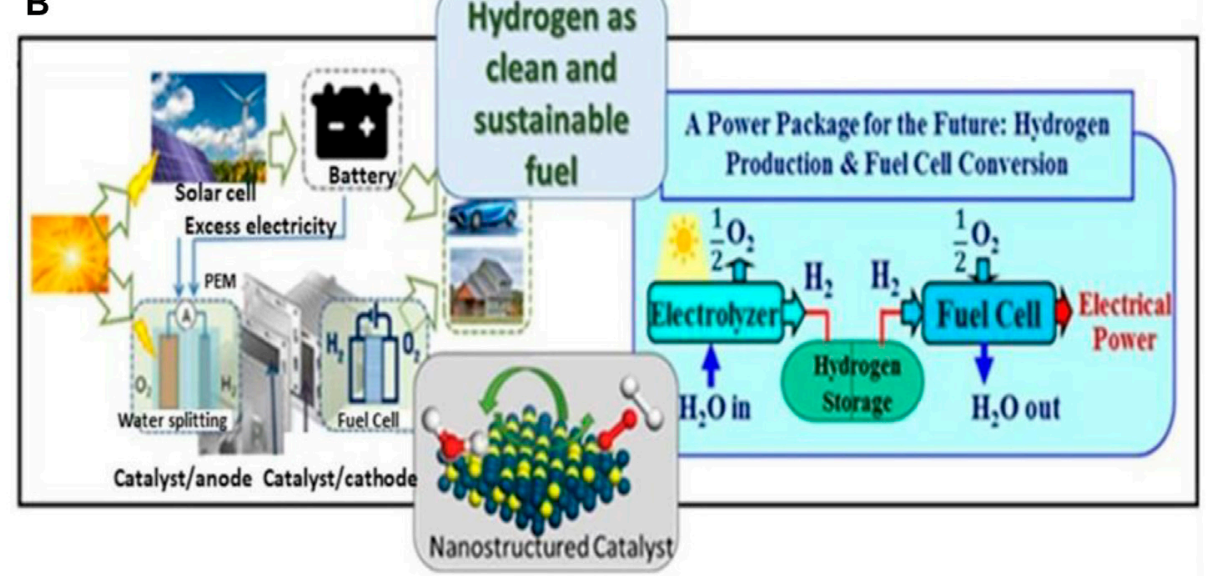

FIGURE 2 | (A) An illustration of the evolution of fuels in terms of hydrogen to carbon ratio. (B) Illustrations of a dual cell functioning as an electrolysis water-splitting cell for hydrogen production from solar energy and a fuel cell for the conversion of hydrogen to electricity, highlighting the sustainable power package of the future and the role of catalysis. Adapted from reference Wang et al. (2021a) Copyright @ 2021 (Springer).

(Wang et al., 2021a). However, when carbon-based catalysts are used during the reaction, carbon-based byproducts are sometimes formed during this process. The thermocatalytic methane decomposition (TMD) is a promising alternative to the existing methods for carbon dioxide free hydrogen production (Harun et al., 2020). Since the process does not include carbon-based products, steps involved in the elimination of carbon oxides are not required. Furthermore, because of the formation of carbon-free products, there is a significant lowering of greenhouse gas production in contrast to the traditional methods (Ashok et al., 2008a). It has also been reported that hydrogen production through this method reduces $\mathrm{CO}_{\mathrm{x}}$ emission by about $27 \%$ and can also reduce the global climatic effects (Weger et al., 2017; Wang et al., 2021a). The decomposition of methane requires a large amount of energy, almost equivalent to its formation. Being functional at very high temperatures, exceeding $1,300^{\circ} \mathrm{C}$, and therefore, the usage of catalysts becomes a necessity to reduce the temperature at which decomposition of methane can easily occur. The present studies have been focused on the development of catalysts that can provide maximum conversion of methane to hydrogen, enhanced activity and stability, and also exhibit low catalytic deactivation (Bockris, 2013; Eljack and Kazi, 2021).

Some of the most commonly used metal catalysts include $\mathrm{Ni}, \mathrm{Fe}$, $\mathrm{Cu}, \mathrm{Co}, \mathrm{Pt}, \mathrm{Pd}$, among others. These catalysts are often used alongside a support structure like silica, $\mathrm{Mg}, \mathrm{Zr}$, Ti and carbon structures to increase the overall surface area of the catalyst. This is important to provide a larger area to function as catalytic active sites during the reaction (Bockris, 2013; Eljack and Kazi, 2021). Among these catalysts, $\mathrm{Ni}$ has gained widespread attention for TMD for hydrogen production, because this element can produce more yield of hydrogen per unit mass of the substrate (Bockris, 2013; Eljack and Kazi, 2021). Moreover, Ni catalysts help form filamentous carbon structures as byproducts that have applications in the nanotechnology field and material sciences (Srilatha et al.,
2017). Yet, metal catalysts are highly susceptible to sulfur poisoning and carbidization and therefore are easily deactivated. Dufour and colleagues have performed several studies on TMD and its applications in hydrogen production (Dufour et al., 2009; Dufour et al., 2012). Through their studies, the authors showed that TMD is a better approach towards hydrogen production because of its eco-friendly nature and could occasionally allow for an autocatalytic activity for a limited time (Serrano et al., 2013; Wang et al., 2021a). TMD has been suggested as a solution for the increasing demand for hydrogen in industries and its use in electricity production (Parkinson et al., 2018). Its economic reliability is dependent on the carbon by-product's value in the market (Keipi et al., 2016). Several kinds of TMD reactors have been explored for the TMD process like the plasma-assisted reactor, molten metal reactor. Besides, many heating points have to be considered to carry out the complete TMD process (Heidenreich et al., 2016; Keipi et al., 2016).

Herein, we provided a detailed overview of hydrogen production via the TMD process. We have discussed thermodynamics and the different methods of hydrogen production. These include, but are not limited to steam methane reforming, partial oxidation of methane, and autothermal reforming. We further discussed the production of hydrogen from renewable sources. These included direct biomass gasification, thermochemical water splitting, methane pyrolysis, aqueous phase reforming, and coal gasification. We have also discussed catalytic deactivation and catalyst regeneration in this review. We finally concluded this article by discussing the future perspectives of the TMD process.

\section{THERMODYNAMICS}

During the TMD reaction, methane molecules are decomposed to give hydrogen (gas) and carbon (solid). That is, 


$$
\mathrm{CH}_{4} \rightarrow 2 \mathrm{H}_{2}+\mathrm{C} \Delta \mathrm{H}^{\mathrm{o}}=74.52 \mathrm{~kJ} / \text { mole }
$$

This reaction is that of TMD via methane pyrolysis and can take place without the requirements of any catalysts (Timmerberg et al., 2020). However, the energy required by the reaction in terms of heat, will be very high (more than $1500 \mathrm{~K}$ ) (Xiao and Varma, 2018). This data implies that the existence of other catalysts that can influence TMD. Therefore, for TMD reactions at lower temperatures, the requirement of catalysts becomes an utmost need (Gmehling et al., 2019). Researchers have reported that gaseous carbon produced is adsorbed on the catalyst and is diffused into it. This occurs due to diffusion driving force (Baker et al., 1972), which is dependent on concentration or temperature changes. The equilibrium constant of the reaction, $\mathrm{K}_{\mathrm{eq}}$, is dependent on the kind of catalyst used can be written as (Ibrahim et al., 2015),

$$
\frac{\mathrm{K}_{\mathrm{eq}}=\left(\mathrm{PH}_{2}^{2}\right)_{\mathrm{eq}} \mathrm{C}^{\mathrm{s}}}{\left(\mathrm{PCH}_{4}\right)_{\mathrm{eq}}}
$$

Here, $C^{s}$ is the solubility of carbon in its active phase, while $\mathrm{P}$ represents the partial pressures of $\mathrm{H}_{2}$ and $\mathrm{CH}_{4}$. Also, $\mathrm{K}_{\mathrm{eq}}$ signifies the equilibrium of the gaseous phase of a carbon mixture having a metal component. The dissolution of filamentous carbon depends on the $\mathrm{K}_{\mathrm{eq}}$ of carbon, which influences the gaseous phase of the threshold while coking (Ibrahim et al., 2015). That is,

$$
\frac{\mathrm{K}_{\mathrm{eq}}=\mathrm{PH}_{2}^{2}}{\mathrm{PCH}_{4}}
$$

The Gibbs energy of TMD also changes with temperature (Villacampa et al., 2003) accordingly:

$$
\begin{aligned}
\Delta \mathrm{G}^{\mathrm{o}}(\mathrm{J} / \text { mole })= & 89658.88-102.27 \mathrm{~T}-0.00428 \mathrm{~T}^{2} \\
& -2499358.99 \mathrm{~T}^{-1}
\end{aligned}
$$

Here, $\mathrm{T}$ is the temperature in Kelvin. The above expressions give an estimated value and not precise values because of the involvement of graphite formation. Moreover, the temperature required for the reaction has to be more than $819 \mathrm{~K}$. In a study by Rostrup-Nielsen and colleagues, it was shown that Gibbs energy of TMD $\left(\Delta \mathrm{G}_{\mathrm{cd}}\right)$ is derived by removing the expression of TMD where graphite formation occurs from the original Gibbs free energy $\left(\Delta G_{a}\right)$ of methane coking (Rostrup-Nielsen, 1972). That is,

$$
\Delta \mathrm{G}_{\mathrm{cd}}=\Delta \mathrm{G}_{\mathrm{a}}-\Delta \mathrm{G}_{\mathrm{o}}
$$

Zhang and Smith suggested the threshold constant $\left(\mathrm{K}_{\mathrm{mf}}\right)$ for carbon during TMD (Zhang and Smith, 2004; Inaba et al., 2019). This constant defines $K_{c}$, the value at which the rate of deactivation of catalyst nears zero because of carbon synthesis. Hence, stable activity and carbon synthesis in TMD using nickel and cobalt as catalysts is affirmed by considering $\mathrm{K}_{\mathrm{m}}$ so that,

$$
\mathrm{K}_{\mathrm{mf}}<\mathrm{K}_{\mathrm{c}}<\mathrm{K}_{\mathrm{m}}
$$

$\mathrm{Ni}$ and Fe catalysts have been rampantly used during the process. Ni based catalysts have shown to have highest activity of $600^{\circ} \mathrm{C}$. Morphologies of spent $\mathrm{Ni} /$ wood char catalyst at different magnification scales However, methane conversion is found to be thermodynamically limited at this high temperature and therefore large amount of hydrogen cannot be produced in concentrated amounts (Abbas and Wan Daud, 2010). Also, Fe based, though highly stable at higher temperatures, get deactivated easily, and hence have shorter lifetime. So, Chesnokov and colleagues modified the catalysts that included $75 \% \mathrm{Ni}-12 \% \mathrm{Cu} / \mathrm{Al}_{2} \mathrm{O}_{3}$ with $\mathrm{Fe}$. This showed high functionality at $700-750^{\circ} \mathrm{C}$ (Chesnokov and Chichkan, 2009) and produced hydrogen products at a high concentration of up to $70 \mathrm{~mol} \%$. Similarly $\mathrm{Ni}-\mathrm{Cu} / \mathrm{Al}_{2} \mathrm{O}_{3}$ catalysts have shown to have considerable advantages over $\mathrm{Ni} / \mathrm{Al}_{2} \mathrm{O}_{3}$ catalysts (Abbas and Wan Daud, 2010). At $600-675^{\circ} \mathrm{C}$, these catalysts have also shown to possess high metal loading capacity and shows high methane conversions. Likewise, in another study by Wang and coworkers, it was observed that $\mathrm{Ni}-\mathrm{Cu}-\mathrm{MgO}$ catalyst also showed high activity and remained active for longer periods of time at temperature ranged between 665 and $725^{\circ} \mathrm{C}$. The authors also noted that this catalysts could produce large amounts of concentrated hydrogen that is devoid of carbon products (Wang and Baker, 2004).

\section{METHODS OF HYDROGEN PRODUCTION}

Currently, hydrogen production surpasses one billion $\mathrm{m}^{3} /$ day. Of this, $48 \%$ of this amount is derived via natural gas, oil contributes to $18 \%$, and over $4 \%$ comes from water-splitting electrolysis (Nikolaidis and Poullikkas, 2017; Hallenbeck et al., 2019). As discussed previously, hydrogen is produced via several methodologies like TMD, catalytic oxidation, and steam gasification (El-Shafie et al., 2019; Harun et al., 2020) (Figure 3). TMD use many catalysts that may range from metal-based catalysts, noble-metal based catalysts, nonsupported catalysts, among others. During the process, a fixed bed reactor is often used (Harun et al., 2020) that contains operating systems for monitoring temperature within the system and the flow rates of the feedstock used.

\section{Hydrogen Production From Fossil Fuels}

Because of the dominance of fossil fuels, hydrogen is derived mostly from them (Kayfeci et al., 2019). The main processes involved in hydrogen production include catalytic steam reforming of light hydrocarbons, partial oxidation of heavy hydrocarbons, coal gasification, and methane decarburization. The most common method used worldwide is the steam reforming of natural gas (Kim et al., 2018). As shown in the Figure 4, the set up required during steam reforming reaction is quite simple and contains a furnace, a temperature modulator, membrane module, flow and gas meters (Kim et al., 2018). This method is far more environmentfriendly and highly efficient ( $\sim 70-80 \%$ ) (Grigoriev et al., 2006; Shiva Kumar and Himabindu, 2019) than other methods that produce hydrogen through fossil fuels (Abe et al., 2019).

\section{Steam Methane Reforming}

Steam methane reforming (SMR) is usually used for industrial purposes to produce hydrogen from methane sources, like from 

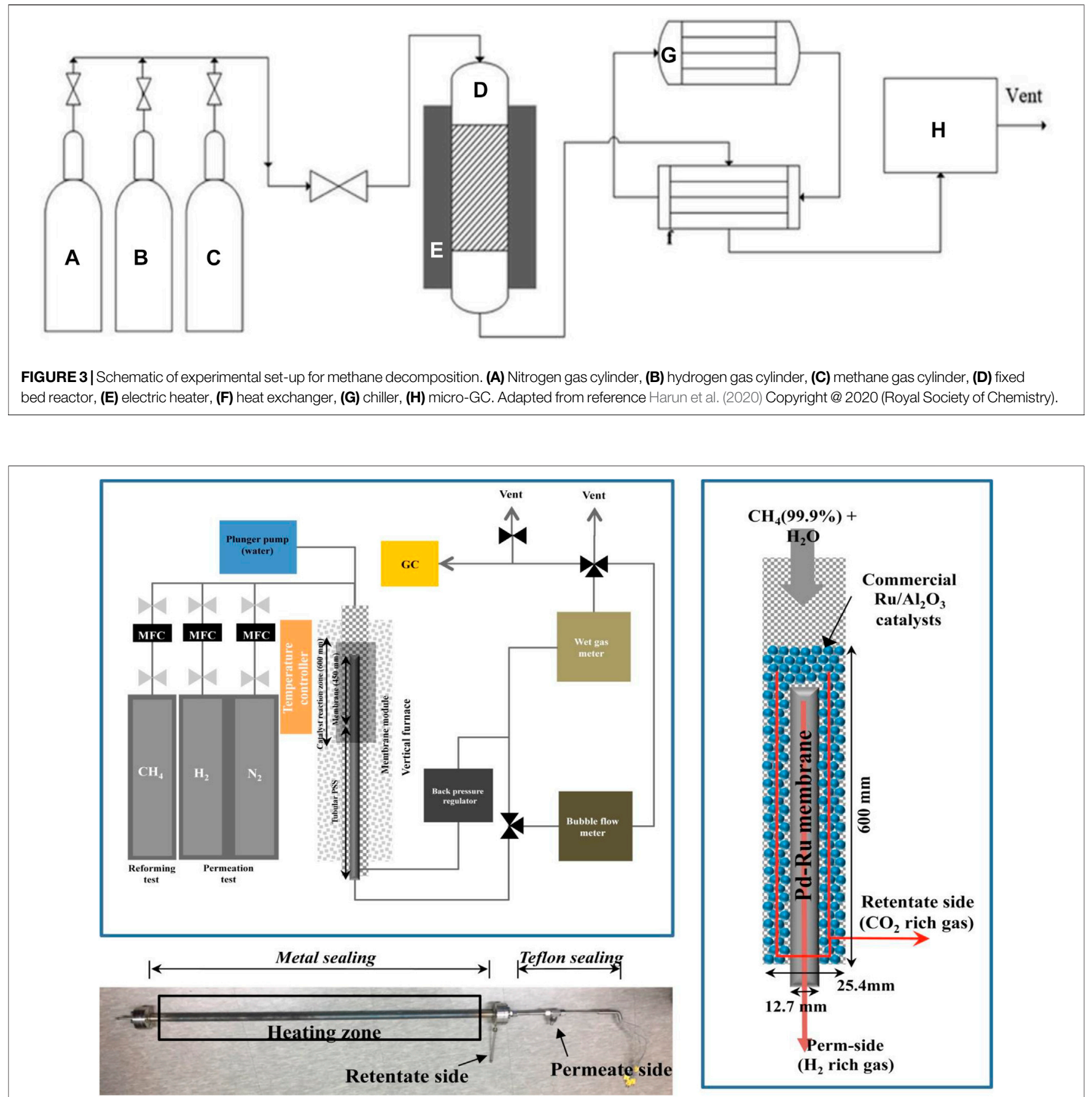

FIGURE 4 | Schematic of the membrane reactor and test setup for steam methane reforming. Adapted from reference Kim et al. (2018) Copyright @ 2018 (Elsevier).

fossil fuels (coal, natural gas, etc.). The process is carried out at a very high temperature of $700-1,000^{\circ} \mathrm{C}$, and pressure ranged between 3 and 25 bar (Chen et al., 2019b; Chen et al., 2020a) (Figure 5). When this reaction is carried out along with the water-gas shift (WGS) reaction, a further reaction occurs between $\mathrm{CO}$ and steam to create additional $\mathrm{H}_{2}$ and $\mathrm{CO}_{2}$ (Ertl et al., 2008).

During the methane steam reforming reaction, hydrogen is formed, further utilized to produce ammonia, methanol, and other hydrocarbons. Two reactions occur during the SMR process.

$$
\begin{gathered}
\mathrm{CH}_{4}+\mathrm{H}_{2} \mathrm{O} \rightleftharpoons \mathrm{CO}+3 \mathrm{H}_{2} \Delta \mathrm{H}_{298}^{0}=205.8 \mathrm{kJmol}^{-1} \\
\mathrm{CO}+\mathrm{H}_{2} \mathrm{O} \rightleftharpoons \mathrm{CO}_{2}+\mathrm{H}_{2} \Delta \mathrm{H}_{298}^{0}=-41 \mathrm{kJmol}^{-1}
\end{gathered}
$$

The mechanism of the reaction determines the activity of the catalyst during the reaction. When the deposition of carbon 


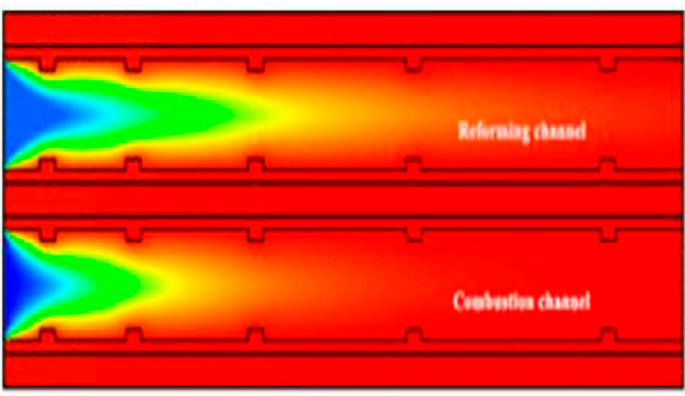

Temperature

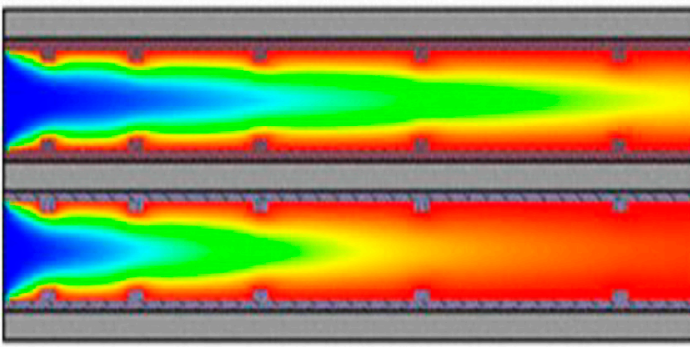

Methane coaversion

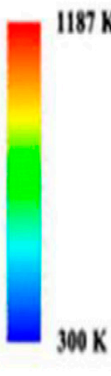

K K

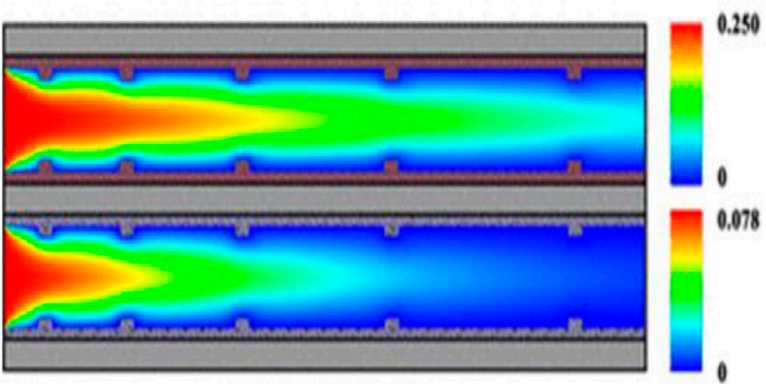

Methane mole fraction

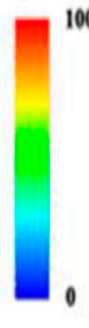

$100 \%$

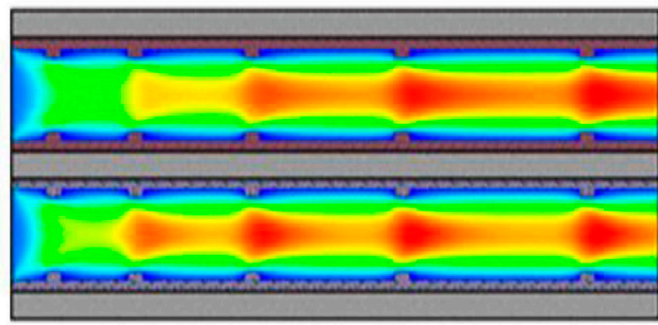

Fuld velocity

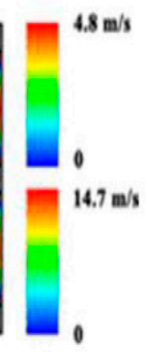

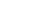

FIGURE 5 | Contour plots of temperature, methane concentration, conversion, and fluid velocity for the reactor. The velocity of the combustible fluid inlet flow is $3.0 \mathrm{~m} / \mathrm{s}$. The velocity of the process fluid inlet flow is $2.0 \mathrm{~m} / \mathrm{s}$. The steam-to-carbon ratio is 3.0, and the equivalence ratio of the combustible mixture at the inlets is 0.8. The thermal conductivity of the material of the dividing wall is 200 W/(m.K). Adapted from reference Chen et al. (2019b) Copyright @ 2019 (American Chemical Society).
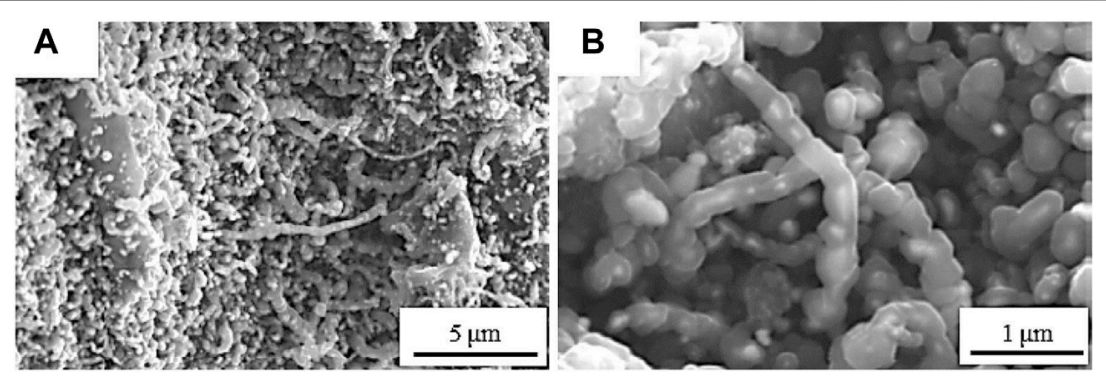

FIGURE 6 | Morphologies of spent Ni/wood char catalyst at different magnification scales. Adapted with permission from reference Hasnan et al. (2020b), copyright@2020 (Springer).

occurs during the dehydrogenation step, it is a competitive reaction and is the rate-determining step. Many studies indicate that, during the reaction, $\mathrm{CO}$ adsorbs on the active sites of the catalysts, forming $\mathrm{CO}_{2}$ (Kramer et al., 2018; Niu et al., 2020). Moreover, there is a considerable increase in the temperature of the reaction during the deposition of carbon and also a formation of a surplus amount of steam during the reaction process.

\section{Partial Oxidation of Methane}

POM is an exothermic reaction that usually gives rise to syngas and other oxygenated compounds like formaldehyde, ethylene, and many hydrocarbons (Chao et al., 2008). Of all the catalysts,
$\mathrm{Ni}$ is the most popularly used in this reaction because it is cheaply available (Daneshmand-Jahromi et al., 2017; Ha et al., 2020). The morphologies of the spent nickel/wood char catalyst is shown in Figure 6.

POM reaction is a far more efficient hydrogen production technique because of the lack of big reactors and mega superheated steam. This is because of the exothermic nature of the reaction (Ghoneim et al., 2016). Moreover, the hydrogen to $\mathrm{CO}$ ratio in this reaction allows for methanol usage and Fischer Tropsch synthesis without any further changes. The stoichiometry of the reaction is as follows:

$$
\mathrm{CH}_{4}+1 / 2 \mathrm{O}_{2} \leftrightarrows \mathrm{CO}+2 \mathrm{H}_{2}
$$


However, this reaction poses a few challenges, such as the inability to control the reaction's selectivity during complete combustion.

\section{Autothermal Reforming}

In the autothermal reforming method (also called the oxidative steam reforming method), oxygen and carbon dioxide react with methane to produce hydrogen. Owing to the oxidation steps in this reaction, it is exothermic. In contrast to the steam methane reforming method, this reaction involves the usage of oxygen. Figure 7 shows this contrast between the two reactions. This main advantage of this method is that, the hydrogen and CO ratio can be monitored (Patil et al., 2007; Carapellucci and Giordano, 2020). This is useful because this process can produce biofuels that need an equal proportion of hydrogen and CO.

The efficiency of ATR depends on hydrogen production. Owing to thermodynamic restriction, low amounts of hydrogen production may potentially hinder the reaction progression. Another limitation of the process is the involvement of air. If air is involved in the reaction, then additional steps are required to separate the products. This, in turn, leads to a higher cost of production (Pinton et al., 2017). The general reaction during autothermal reforming is:

$$
\begin{aligned}
& \mathrm{C}_{\mathrm{x}} \mathrm{H}_{\mathrm{y}} \mathrm{O}_{\mathrm{z}}+[2 \mathrm{x}-(\mathrm{z}+1)] \mathrm{H}_{2} \mathrm{O}+1 / 2 \mathrm{O}_{2} \rightarrow \mathrm{xCO}_{2} \\
& +\frac{2[2 \mathrm{x}-(\mathrm{z}+1)]}{2}+\mathrm{yH}_{2}
\end{aligned}
$$

For instance, during ATR of ethanol, combinational reaction is carried out simultaneously (Chen et al., 2009). These include partial oxidation follow by steam reforming. The following reactions occur:

$$
\begin{gathered}
\mathrm{C}_{2} \mathrm{H}_{5} \mathrm{OH}+1 / 2 \mathrm{O}_{2} \rightarrow 2 \mathrm{CO}+3 \mathrm{H}_{2} \\
\mathrm{C}_{2} \mathrm{H}_{5} \mathrm{OH}+1 / 2 \mathrm{O}_{2}+2 \mathrm{H}_{2} \mathrm{O} \rightarrow 2 \mathrm{CO}_{2}+5 \mathrm{H}_{2}
\end{gathered}
$$

These reactions occur in between 500 and $800^{\circ} \mathrm{C}$ (Chen et al., 2009).

\section{Hydrogen Production From Renewable Sources}

Despite the rampant production of hydrogen from fossil fuels, those methodologies pose serious concerns, especially environment-related issues and higher production costs. Being a greenhouse gas, it poses a lot of concern towards environmental sustainability. Hence, hydrogen production's better alternative is from renewable resources like geothermal sources, biomass, wind energy, etc., (Avc1oğlu et al., 2019). There are methods available that permit the chemical conversion of renewable resources to give rise to hydrogen. Such strategies include biomass gasification, steam reforming, among others. The hydrogen produced is used in metallurgical purposes, electronics development, and various other chemical applications (Srilatha et al., 2017).

\section{Direct Biomass Gasification}

The main reactions in DBG are endothermic in nature and involves partial oxidation processes (Kumar et al., 2017; Salam

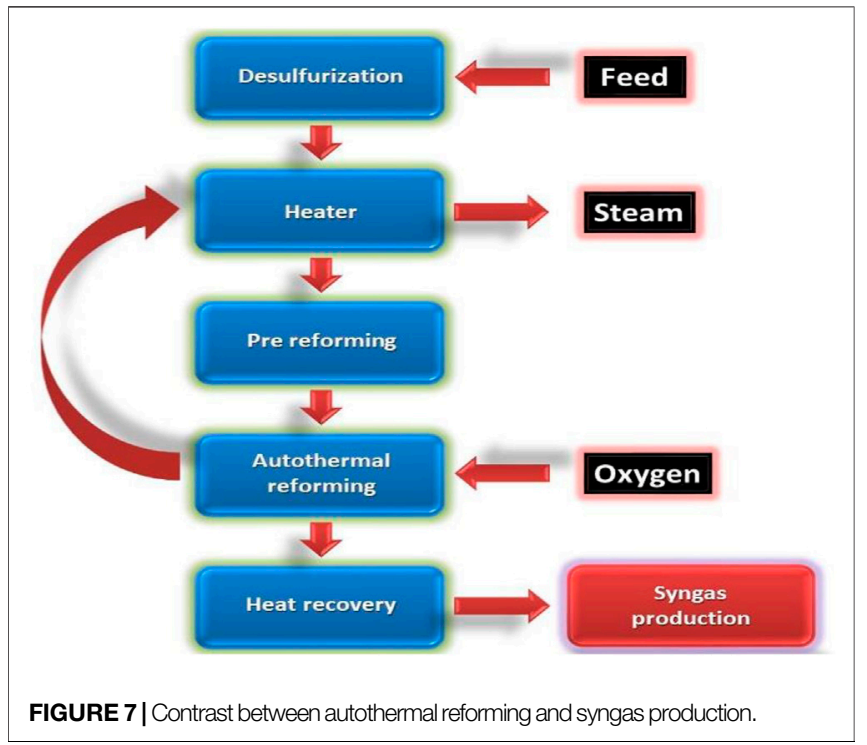

et al., 2018). The energy for the reaction is provided by the oxidation of biomass via autothermal reaction. There are four main steps involved in this process: oxidation, drying, pyrolysis, and reduction. The general stoichiometry of the main reaction (Molino et al., 2016) that occurs during the gasification process is:

$$
\mathrm{nCO}+2 \mathrm{nH}_{2} \rightarrow \mathrm{C}_{\mathrm{n}} \mathrm{H}_{2 \mathrm{n}}+\mathrm{OH}+(\mathrm{n}-1) \mathrm{H}_{2} \mathrm{O}
$$

A flow diagram depicting the hydrogen production via biomass gasification is shown in Figure 8 (Salam et al., 2018). The set up requires limited air or steam that functions as gasifying agents. Scrubbers like RME and water scrubbers are used to clean and dry during the process. To remove any carbon based products formed during the process, a special membrane separation unit is present. Then a pressure swing adsorption (PSA) channel is present that gives concentrated hydrogen products.

\section{Thermochemical Water Splitting}

The TWS process involves a direct transformation of thermal energy to hydrogen. Hydrogen is produced in abundance and hence serves as an energy carrier in various techniques (Safari and Dincer, 2020). The reaction is carried out at very high temperatures - above a thousand degrees. The reaction occurs by simultaneously carrying two chemical reactions. First, elevated temperature endothermic process and lowered temperature exothermic process. This reaction's net result is a thermochemical water-splitting process that gives an abundance of free energy post-reaction (Budama et al., 2021). In the thermo catalytic reaction (Figure 9), the metal catalyst (usually metal oxide) undergoes reduction during the first endothermic step. This step is also called the activation step. In this step, oxygen is given out, further reacting with water in the hydrolytic step. The second step is an exothermic reaction to finally give out hydrogen and oxide - which is then recycled in the previous step (Safari and Dincer, 2020).

The splitting of hydrogen and oxygen is an uphill reaction. A significant positive change in Gibbs free energy is observed during 


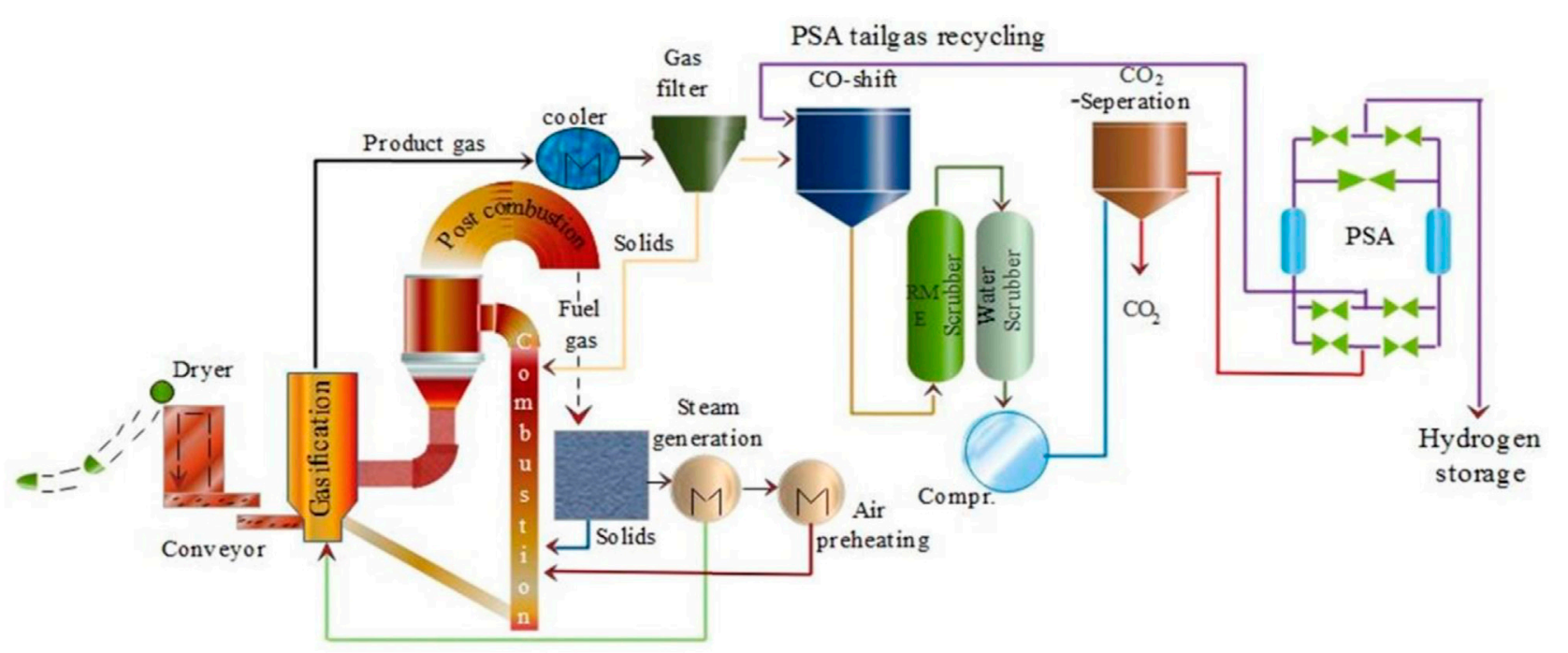

FIGURE 8 | Process flow diagram of biomass to hydrogen. Adapted from reference Salam et al. (2018) Copyright @ 2018 (Elsevier).

this reaction. This means $\Delta \mathrm{G}^{0}=237 \mathrm{~kJ} / \mathrm{mol}$ is produced during the reaction. Hence, because of the high energy of the reaction, it is also called artificial photosynthesis.

$$
\mathrm{H}_{2} \mathrm{O}(\mathrm{l}) \rightarrow \mathrm{H}_{2}(\mathrm{~g})+1 / 2 \quad \mathrm{O}_{2}(\mathrm{~g})
$$

The energy for the reaction is made available for splitting $\mathrm{H}-\mathrm{O}-\mathrm{H}$ bonds is provided by electrical, electromagnetic, or thermal sources. The process is carried out by transferring electrical current into the water. Here, the chemical energy is produced from electrical energy (Landman et al., 2017). At the anode, water disintegrates into five oxygen and protons. While at the cathode, hydrogen is produced.

\section{Methane Pyrolysis}

When hydrogen is produced by decomposing methane, the reaction method is referred to as pyrolysis or MP, or methane cracking. In this process, methane gets split into its component elements that are $\mathrm{H}_{2}$ and solid C. The combustion of carbon does not occur within this process. In this method, hydrogen is produced inexpensively when compared to steam methane reforming. Moreover, $\mathrm{CO}_{2}$ capture and storage (CCS) also occur during this process (Timmerberg et al., 2020; Leal Pérez et al., 2021). The reason for the cheap reaction process could be the production of solid carbon. This solid carbon is precious and hence compensates for the costs of the entire process. The process of methane pyrolysis undergoes the chemical splitting of methane. The resultant compounds include hydrogen and hydrocarbons, along with solid carbon molecules (Timmerberg et al., 2020).

$$
\mathrm{CH}_{4}(\mathrm{~g}) \rightarrow \mathrm{C}(\mathrm{s})+2 \mathrm{H}_{2}(\mathrm{~g}) \Delta \mathrm{H}_{298 \mathrm{~K}}=74.52 \mathrm{~kJ} / \mathrm{mol}
$$

The process is endothermic and derives energy from various sources. Since oxygen is not involved in the reaction, no carbon dioxide or its derivatives are produced. Hence there are no further separation processes required during the reaction and, therefore,

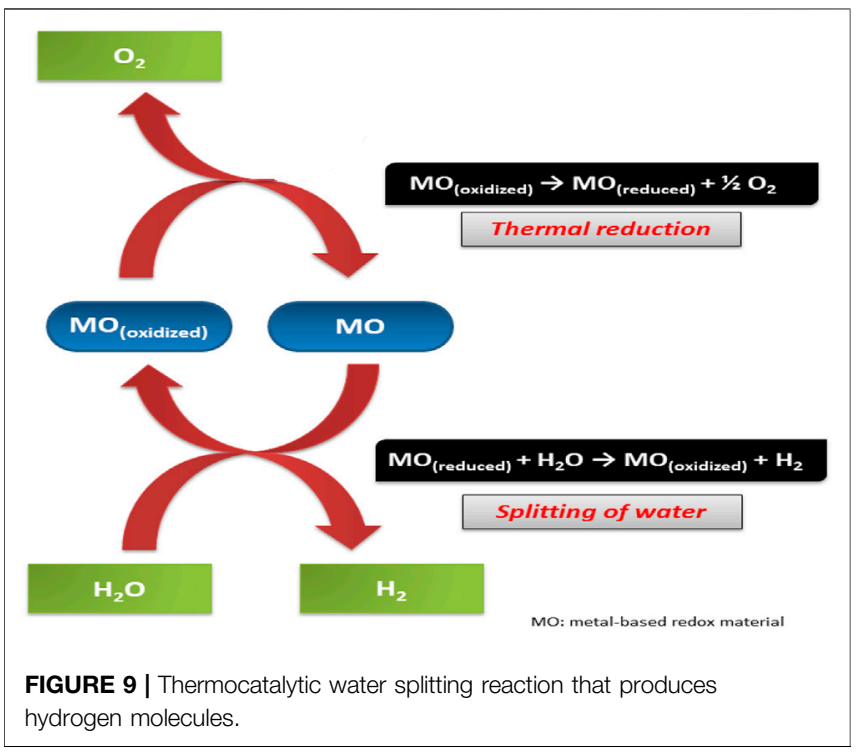

are less complicated. However, sometimes the hydrogen produced may need to undergo further processing to remove any mixture's impurities. When only hydrogen is expected to be the sole product, then the reaction's total efficiency remains 59\%, and the rest gets trapped in the solid carbon produced.

\section{Aqueous Phase Reforming}

APR also synthesizes hydrogen from biomass, including sugar, glycerol, and oxygenated compounds. This reforming is carried out in a liquid state of the reactants. The major plus point of this reaction is that hydrogen is produced without the evaporation of water. This, therefore, saves a lot of energy during the process.

APR was first developed by Davda and colleagues (Davda et al., 2005). In the first step, water is added to the reactant 
biomass. This gets separated into aqueous and organic phases. The aqueous phase is then transported to another hydrogenation area where hydrogenation of the aqueous phase occurs. In the hydrogenation step, hydrogen is synthesized via APR (Vispute and Huber, 2009). Glucose is also used as a reactant during the APR reaction for hydrogenation. Glucose is an ideal candidate because of the reduction in the number of reaction steps (Fasolini et al., 2019): glucose is synthesized during the aqueous stream. APR of glucose can be shown as:

$$
\mathrm{C}_{6} \mathrm{H}_{12} \mathrm{O}_{6}+6 \mathrm{H}_{2} \mathrm{O} \rightarrow 12 \mathrm{H}_{2}+6 \mathrm{CO}_{2}
$$

In general, the reaction can be expressed as:

$$
\mathrm{C}_{\mathrm{n}} \mathrm{H}_{2 \mathrm{y}} \mathrm{O}_{\mathrm{n}} \rightarrow \mathrm{nCO}+\mathrm{yH}_{2}
$$

This reaction, however, is oversimplified and is not a direct reaction. There are several intermediates formed during the reaction. Hydrogenation of $\mathrm{CO} / \mathrm{CO}_{2}$ results in the formation of alkanes. On the other hand, dehydration gives ketones and aldehydes.

\section{Coal Gasification}

This technology of CG is a recent development. This process has many advantages, for instance, high solubility, transfer of mass, and quick heating of coal (Stiegel and Ramezan, 2006). Moreover, low carbon deposition on the catalysts occurs, and the gasification process is highly efficient. Coal is changed to abundant hydrogen gas at lower temperatures in contrast to the conventional gasification processes. Furthermore, compounds having an abundance of nitrogen and sulfur are wholly converted in the aqueous phase (Williams et al., 2018). This, therefore, reduces the overall pollution of the reaction.

During coal gasification, coal undergoes a reaction with steam and air (containing oxygen). During the reaction, organic material reacts in the presence of a catalyst(s) to give carbonmonoxide, hydrogen, methane, and small concentrations of other gases containing nitrogen and sulfur. Ash (char) is also produced as a product (Widjaya et al., 2018). During volatilization, the general stoichiometry of the reaction is:

$$
4 \mathrm{C}_{\mathrm{n}} \mathrm{H}_{\mathrm{m}} \rightarrow \mathrm{mCH}_{4}+(4 \mathrm{n}-\mathrm{m}) \mathrm{C}
$$

During the char gasification step, the following reaction occurs:

$$
\begin{gathered}
\mathrm{C}+\mathrm{H}_{2} \mathrm{O} \rightarrow \mathrm{CO}+\mathrm{H}_{2} \\
\mathrm{C}+\mathrm{CO}_{2} \rightarrow 2 \mathrm{CO} \\
\mathrm{C}+2 \mathrm{H}_{2} \rightarrow \mathrm{CH}_{4}
\end{gathered}
$$

The gas-phase reactions include:

$$
\begin{gathered}
\mathrm{CO}+{ }_{-} \mathrm{O}_{2} \rightarrow \mathrm{CO}_{2} \\
\mathrm{H}_{2}+\mathrm{O}_{2} \rightarrow \mathrm{H}_{2} \mathrm{O} \\
\mathrm{H}_{2} \mathrm{O}+\mathrm{CO} \rightarrow \mathrm{H}_{2}+\mathrm{CO}_{2} \\
\mathrm{CO}+3 \mathrm{H}_{2} \rightarrow \mathrm{CH}_{4}+\mathrm{H}_{2} \mathrm{O}
\end{gathered}
$$

The rates at which the complexes are formed and removed; and the number of active sites occupied on the catalyst's surface determine every individual step's rate and order.

\section{CATALYSTS}

Catalysts are most commonly synthesized by the process of impregnation owing to its simplicity at laboratory and industrial levels. The process involves impregnation of porous support substances in the presence of metal oxide solutions (Van Dillen et al., 2003). Then the solvent is evaporated giving the desired catalyst. However, there is a limited reaction between the metal precursor and support, and also the solvent evaporates over the support particles causing a capillary flow of the solution. Thus the formation of egg shell catalysts occurs that do not possess good active phase dispersion. In the ground breaking work done by Kotter and Riekert, it was discovered that with an increase in viscosity of impregnating solution, the outward flow of the solution reduces that causes a better activity on supporting elements (Van Dillen et al., 2003). Other processes involved in catalyst synthesis show either extremely high or extremely low drying rates with moderate quality type of products (Jackson, 1995).

\section{Metal Catalysts}

Metal catalysts like $\mathrm{Ni} / \mathrm{Al}_{2} \mathrm{O}_{3}$ are better preferred during SMR reactions because of their inexpensive nature (Siew et al., 2014). The most extensively studied metal catalysts for this process are from the VIII group of the periodic table. Their properties, like the size effect (Vogt et al., 2020), support effect (Wang et al., 2018), promoter effects (Cao et al., 2020), and coordination states (Rogers et al., 2016), have also been well researched. Even the external conditions of methane reforming like the temperature, pressure, and kind of reactor used, are considered while using the metal catalysts.

Transitions metals like $\mathrm{Fe}$ and $\mathrm{Ni}$ that have semi-filled d-orbitals are also used in SMR reactions because of their enhanced stability and activity (Syed Muhammad et al., 2018; Inaba et al., 2019). Ni catalysts are far more convenient for TMD via SMR reactions when carried out at $500-600^{\circ} \mathrm{C}$. However, this temperature range is lower than the conditions needed to achieve an equilibrium state because $\mathrm{Ni}$ deactivates at higher temperature conditions. On the contrary, Fe functions efficiently at increased temperatures and is comparatively less expensive (Frontera et al., 2017). The most commonly used metal catalysts are the transition metal catalysts like $\mathrm{Ni}, \mathrm{Co}$, and Fe. Because of the enhanced turnover rates and being cheaply available, $\mathrm{Ni}$ catalysts are better preferred. Studies have also shown that, in the presence of elements like rhodium, Ni gets easily reduced, which increases the methane conversion, thereby increasing the total hydrogen production (Kim et al., 2015). Table 1 shows the data related to a few recent reports about hydrogen production via POM method using Ni-based catalysts supported on various catalysts.

Like the other processes, the most widely used metal catalyst is based on the transition element, Ni (Farsi and Mansouri, 2016), because of its cheap availability and reaction efficiency. The $\mathrm{Ni}$ available in the catalyst system usually remains below $20 \%$ due to its highest activity observed at that concentration (Haynes and Shekhawat, 2011; Scapinello et al., 2017). This could occur because of a decrease in $\mathrm{Ni}$ dispersion with increasing $\mathrm{Ni}$ amount. Studies have reported that catalysts prepared via 
TABLE 1 | Various Ni-based metal catalysts used for hydrogen production via POM method.

\begin{tabular}{|c|c|c|c|c|c|}
\hline Metal & Support & Methane conversion (\%) & Catalyst preparation method & $\mathrm{H}_{2} / \mathrm{CO}$ & References \\
\hline $\mathrm{Rh}-\mathrm{Ni}$ & $\mathrm{Al}_{2} \mathrm{O}_{3}$ & $\sim 90$ & Wet impregnation and solid-state reaction & $\sim 2$ & Alvarez-Galvan et al. (2019) \\
\hline $\mathrm{Rh}-\mathrm{Ni}$ & $\mathrm{CeO}_{2}$ & $\sim 80$ & Wet impregnation and solid-state reaction & $\sim 2$ & Alvarez-Galvan et al. (2019) \\
\hline $\mathrm{Rh}-\mathrm{Ni}$ & $\mathrm{La}_{2} \mathrm{O}_{3}$ & $\sim 50$ & Wet impregnation and solid-state reaction & $\sim 2$ & Alvarez-Galvan et al. (2019) \\
\hline $\mathrm{Rh}-\mathrm{Ni}$ & $\mathrm{MgO}$ & $\sim 50$ & Wet impregnation and solid-state reaction & $\sim 2$ & Alvarez-Galvan et al. (2019) \\
\hline $\mathrm{Rh}-\mathrm{Ni}$ & $\mathrm{ZrO}_{2}$ & $\sim 50$ & Wet impregnation and solid-state reaction & $\sim 2$ & Alvarez-Galvan et al. (2019) \\
\hline $\mathrm{Ni}$ & $\mathrm{Al}_{2} \mathrm{O}_{3}$ and $\mathrm{ZrO}_{2}$ & 90 & Wet-impregnation method & 2 & Fakeeha et al. (2020) \\
\hline
\end{tabular}

\begin{tabular}{|c|c|c|c|c|}
\hline Metal & Support & Methane conversion (\%) & $\mathrm{H}_{2} / \mathrm{CH}_{4}$ & References \\
\hline $\mathrm{Ni}$ & $\mathrm{SiO}_{2} \mathrm{Al}_{2} \mathrm{O}_{3}$ & $\sim 100 \%$ & 1 & Ali et al. (2016) \\
\hline $\mathrm{Ni}$ & $\mathrm{MgAl}_{2} \mathrm{O}_{4}$ & $\sim 75 \%$ & 5 & Katheria et al. (2016) \\
\hline $\mathrm{Ni}$ & $\mathrm{Ni}_{2} \mathrm{Al}_{2} \mathrm{O}_{5}$ & $82 \%$ & 2.4 & Rogers et al. (2016) \\
\hline $\mathrm{Ni}$ & $\mathrm{ZnLaAlO}_{4}$ & $\sim 72 \%$ & 3 & Khani et al. (2016) \\
\hline Pt & $\mathrm{ZnLaAlO}_{4}$ & $\sim 88 \%$ & 3 & Khani et al. (2016) \\
\hline $\mathrm{Ru}$ & $\mathrm{ZnLaAlO}_{4}$ & $\sim 72 \%$ & 3 & Khani et al. (2016) \\
\hline $\mathrm{Ni}$ & $\gamma$-Al2O3 & $\sim 98 \%$ & 3 & Khani et al. (2016) \\
\hline
\end{tabular}

\begin{tabular}{|c|c|c|c|c|}
\hline Metal & Support & Methane conversion (\%) & $\mathrm{H}_{2} / \mathrm{CO}$ & References \\
\hline $\mathrm{Ni}$ & $\mathrm{Al}_{2} \mathrm{O}_{3}$ & 86.17 & 1.49 & Peng et al. (2017) \\
\hline $\mathrm{Ni}$ & $\mathrm{CeO}_{2} / \mathrm{Al}_{2} \mathrm{O}_{3}$ & 93.65 & 1.84 & Peng et al. (2017) \\
\hline $\mathrm{Ni}$ & $\mathrm{Ru} / \gamma-\mathrm{Al}_{2} \mathrm{O}_{3}$ & 80 & 1.5 & Calzada Hernandez et al. (2020) \\
\hline $\mathrm{Ni}$ & MCM-41 & $\sim 100$ & 3.85 & Akubo et al. (2020) \\
\hline
\end{tabular}

microwave assistance impregnation methods show enhanced activity (Hosseini et al., 2017). Moreover, microwave radiations enhance the rate at which $\mathrm{Ni}$ gets deposited on the catalyst's surface during their preparation. The efficiency of such a catalyst and their influence in methane reforming reactions was observed in the studies carried out by Roh and colleagues (HS et al., 2002). The authors explained this behavior by the catalysts due to the high interaction with the catalysts' active phase. Table 2 shows the data related to a few recent reports about hydrogen production via autothermal reforming reactions.

Many catalysts like the ones based on nickel, zeolites, alumina, platinum, ruthenium, and others based on alkali metals have been studied (Okolie et al., 2019). Ni-based catalysts have shown highend results during the gasification process because of their ability to allow reforming reactions (Nikolaidis and Poullikkas, 2017). Studies have revealed that alumina silicate-based catalysts are far more effective than Ni-based catalysts during the gasification process (Arregi et al., 2018). Nickel-based catalysts are often used when hydrogen is the only product needed. Its activity is dependent on the presence or absence of the support material and other additives (Kannaiyan et al., 2016). Table 3 shows the data related to a few recent reports about hydrogen production via direct biomass gasification method using Ni-based catalysts supported on various catalysts.

Metal catalysts show enhanced activity and high chemical and mechanical efficiency and stability during the water-splitting reaction. Metals like $\mathrm{Ni}, \mathrm{Co}, \mathrm{Pt}$, and others are very commonly used during the reaction (Konsolakis et al., 2016). Among these,
Ni catalysts have shown the highest effectiveness for hydrogen production because of the resultant large yield during the reaction (Saikia et al., 2020; Wang et al., 2021b). However, metal poisoning by sulfur and carbon deposition on their actives sites results in metal deactivation. Hence, even carbon-based catalysts are used to overcome the shortcomings of metal-based catalysts (Dufour et al., 2010; Harun et al., 2020).

Most metal catalysts that are used in this reaction get deactivated on carbon deactivation on their surface. The separation of the coke deposited on the surface can be a cumbersome process. We have discussed catalyst reactivation in the following sections. Because of the additional reactivation process for catalysts, sometimes no catalysts are preferred. Moreover, metal-based catalysts are also promising entities for the process because they still show better stability and efficiency than carbon-based catalysts.

Among the commonly used metal catalysts, nickel has shown high conversion rates even at $500^{\circ} \mathrm{C}$ temperatures. While, without a catalyst, the reaction proceeds at a higher temperature of $700^{\circ} \mathrm{C}$ (Brandon and Kurban, 2017). Apart from $\mathrm{Ni}$, even $\mathrm{Fe}$-based catalysts have shown to be inexpensive and widely used for the industrial production of hydrogen via methane pyrolysis (Qian et al., 2020). APR reactions that produce hydrogen have been studied for various catalysts, including iron, nickel, palladium, rhodium, iridium, etc. These elements have been noted to show high activity as catalysts during aqueous phase reforming for hydrogen production. Among these, platinum, palladium, 
TABLE 4 | Various Pt-based metal catalysts used for hydrogen production via APR method.

\begin{tabular}{|c|c|c|c|c|}
\hline Metal & Support & Hydrogen yield & Conversion (\%) & References \\
\hline $\mathrm{Pt}$ & CMK-3 & $57.5 \%$ & 79.4 & Kim et al. (2012a) \\
\hline $\mathrm{Pt}$ & CMK-9 & $94.2 \%$ & 89.2 & Kim et al. (2012a) \\
\hline $\mathrm{Pt}$ & CMK-3-MCN-R & $71.7 \%$ & 84.7 & Jeong et al. (2014) \\
\hline $\mathrm{Pt}$ & CMK-5-MCN-R & $8.6 \%$ & 88 & Jeong et al. (2014) \\
\hline Pt-Re & CMK-3 & $19.9 \mathrm{~cm}^{3} /\left(g_{\text {cat }} \cdot \min \right)$ & 44.2 & Kim et al. (2012b) \\
\hline Pt-Ni & $\gamma-\mathrm{Al}_{2} \mathrm{O}_{3}$ & - & 80 & De Vlieger et al. (2012) \\
\hline Pt-Fe & $\gamma-\mathrm{Al}_{2} \mathrm{O}_{3}$ & $48.1 \mathrm{~cm}^{3} /\left(\mathrm{g}_{\mathrm{cat}} \cdot \mathrm{min}\right)$ & 48.1 & Huber et al. (2006) \\
\hline Pt-Re & CMK-3 & $36.6 \mathrm{~cm}^{3} /\left(g_{\mathrm{cat}} \cdot \mathrm{min}\right)$ & 89.3 & Kim et al. (2012b) \\
\hline
\end{tabular}

TABLE 5 | Various Ni-based metal catalysts used for hydrogen production via methane reforming reactions.

\begin{tabular}{|c|c|c|c|c|}
\hline Metal & Support & Methane conversion (\%) & $\mathrm{H}_{2} / \mathrm{CO}$ & Ref \\
\hline $\mathrm{Ni}-\mathrm{Co}$ & $\mathrm{Al}_{2} \mathrm{O}_{3}-\mathrm{MgO}$ & 79.17 & 1 & Abd Ghani et al. (2018) \\
\hline $\mathrm{Ni}$ & Nd-mesoporous silica & 53 & 0.75 & Li et al. (2017) \\
\hline Magnesium-NiO & Mesoporous zirconia & 82 & 0.94 & Al-Fatesh et al. (2020) \\
\hline $\mathrm{Ni}$ & MSC-1 & 85 & $\sim 1$ & Zhang et al. (2019b) \\
\hline $\mathrm{NiO}$ & $\mathrm{MgO}-\mathrm{Al}_{2} \mathrm{O}_{3}$ & 91 & $\sim 1$ & Chai et al. (2017) \\
\hline $\mathrm{Ni}$ & La@KCC-1 & $\sim 96$ & $\sim 1$ & Abdulrasheed et al. (2020) \\
\hline $\mathrm{Ni}$ & $\mathrm{Ce}-\mathrm{ZnAl}{ }_{2} \mathrm{O}_{4}$ & 82 & 1 & Movasati et al. (2017) \\
\hline
\end{tabular}

and nickel-tin alloys have displayed enhanced activity from hydrogen production. It has been noted that when and if the supports demonstrate basic or neutral nature, then the selectivity during hydrogen production and its selectivity increases. Table 4 shows the data related to a few recent reports about hydrogen production via APR method using Pt-based catalysts supported on various catalysts.

As in the previously discussed methodologies for hydrogen production, Ni-based catalysts have the maximum catalytic activity and efficiency. It helps in adjusting the ratio of $\mathrm{CO}_{\mathrm{x}}$ and hydrogen during the conversion of methane. The highest activity of this catalyst is observed at $780^{\circ} \mathrm{C}$ (Widjaya et al., 2018). However, as discussed previously, the Ni catalysts get deactivated due to carbon deposits. On the contrary, $\mathrm{Ni}$ is relatively cheap and readily available; hence, it is an ideal catalyst and shows optimal activity.

\section{Metal Supported Catalysts}

Metal supported catalysts like catalysts supported by $\mathrm{Ni}$ are also preferred in SMR reactions. They are relatively cheaper and available with ease. Moreover, they show enhanced activity. This was observed in the study carried out by Karaismailoglu and colleagues (Karaismailoglu et al., 2019). They used Nibased catalysts attached to yttria. The authors developed a catalyst via the sol-gel method. They noticed its activity between 390 and $845^{\circ} \mathrm{C}$ and observed that the maximum amount of coke was formed when the temperature was elevated. Few studies indicate that methane decomposition can occur without the reduction of catalysts (Musamali and Isa, 2018). Such methods are relatively more inexpensive. Moreover, it has been noted that hydrogen production reduces this way. Table 5 shows the data related to a few recent researches about hydrogen production via SMR method using Ni-based catalysts supported on various catalysts.
The most commonly used metal-supported catalysts during the direct biomass gasification process include Ni-based catalysts having $\mathrm{K}_{2} \mathrm{CO}_{3}$ support. Even fundamental catalysts like $\mathrm{MgO}$ and $\mathrm{CaO}$ are also used during the reaction (Anis and Zainal, 2011). However, these metal-supported catalysts make use of sorbents that are eco-friendly to enhance the catalyst's overall sensitivity. Limitations also persist in the noble metal-supported catalysts that the ones supported by rhodium (Asadullah et al., 2004). Among the metal catalysts like nickel, cobalt, palladium, iron, and others, none of these shows a very high efficiency on their own during the thermo catalytic water splitting reactions. Hence elements like silica, alumina, magnesia, carbon are used simultaneously along with the core catalysts. These metal support catalysts enhance the total available surface area on the catalyst so that more active sites can be made available to enhance the reaction process (Srilatha et al., 2017).

The second metal support is introduced in a catalyst to increase the life of the catalyst. For instance, when the second metal support is introduced in Ni-based catalysts, the activity and its stability have shown to be exponentially increased (SánchezBastardo et al., 2020). The most popularly used metal-supported catalysts include the ones supported by palladium and copper. Because of the larger surface area, the catalyst deactivation does not occur immediately, and hence the catalysts remain stable for longer durations. The support available for the catalysts allows for equilibrium between the methane dissociation and carbon diffusion rates. Certain metals like palladium and copper enhance the reduction process. Moreover, weak bonds between metals and their supports also improve metals' reducing capacity; when there are strong bonds between metal and the support in a catalyst, the catalyst's dispersion and stability increases.

Tao and colleagues studied the effect of nickel-iron-cobalt alloy in APR reaction (Tao et al., 2020). The authors observed that the nickel-iron allowed for better catalytic activity during the 
reaction than the lone nickel and iron catalysts. Moreover, when cobalt is added to the catalyst, the catalyst's overall activity was shown to increase. A higher conversion rate of the reactants was observed in aqueous phase reforming, and more hydrogen production was recorded. Moreover, the selectivity of hydrogen was also shown to increase tremendously. This catalyst was shown to undergo reduction at even low temperatures of $300^{\circ} \mathrm{C}$. However, the activity was recorded to increase with increasing temperature. Maximum activity was observed at $\sim 660^{\circ} \mathrm{C}$.

Earth metal catalysts have been shown to play a useful role during hydrogen production during coal gasification. Dolomite $\left(\mathrm{CaCO}_{3} \cdot \mathrm{MgCO}_{3}\right)$ has very high efficiency and does not need to undergo any regeneration after the catalytic process (Widjaya et al., 2018). Other than those, nickel-aluminum catalysts and nickel-olivine catalysts have also shown practical usage during coal gasification of methane for hydrogen production (Mei Wu et al., 2014). Ni-based catalysts, in general, are involved in removing tars and excess methane.

\section{Non-Supported Catalysts}

Studies also indicate that the performance of a given catalyst for TMD depends on the material of carbon used as the support (Yang et al., 2015). Among these, graphene has better activity when compared to unsupported catalysts (Hasnan et al., 2020a). This was seen in the work of Lua and Wang (2013). They studied non supported Ni-based catalysts in TMD and discovered that $\mathrm{CH}_{4}$ must be inserted in the reaction mixture at a reduced temperature for an efficient reaction process. Unsupported catalysts like $\mathrm{NiCuAl}$ (Suelves et al., 2006) and $\mathrm{NiCuMg}$ (Moliner et al., 2008) exhibit high activity and stability. They provide an opportunity to develop metal crystals that allow for the reaction to proceed for prolonged durations. Hence, nonsupported catalysts also play a vital role in hydrogen production. Despite being cheaply available, transition metal catalysts like the ones based on $\mathrm{Ni}$ are easily deactivated when on stream. This may occur because of frittage, deposition of carbon on the surface, or further reactions with the substrates (Pantaleo et al., 2016). The activity of these catalysts depends on their active forms and the support used during the reaction. The size of the metal particles is an essential feature that determines their intrinsic activity and their deactivation rate. These features are found to be inversely proportional to the size of the metal particles (Kosinov et al., 2019).

When another metal is attached to these metal-based catalysts like Ni-based catalysts, the resultant catalyst's stability dramatically increases. Metals like rhodium, platinum, palladium, iridium have been used in metal catalysts to improve their overall strength. This has been seen in many studies (Alvarez-Galvan et al., 2019). Of all the metals used to support other metal catalysts, rhodium is the most promising of all (Tanaka et al., 2010). This is because it aids in the non-noble metal to remain a metal by disallowing the excess transfer of hydrogen atoms from noble metal to non-noble metal catalysts (Arandiyan and Li, 2012). As discussed above, Ni catalysts serve as the most popular option for catalysts during hydrogen production. Apart from this, palladium, copper, and other metals are also used as catalysts. However, these metals alone sometimes lead to the deactivation of the catalysts. This happens because of the carbon deposition at the catalysts' surface.

This deactivation can be prevented by adding metals like iron, platinum, gold, etc., along with the primary metal catalyst to improve the catalysts' overall activity and efficiency. This was shown in a study done by Dantas and colleagues (Dantas et al., 2010). The scientists reported that the catalyst supported on silver allowed for the increased conversion of methane and accounted for the stability of the catalyst function and activity. In another study, Kaori Yoshida and coworkers discovered that Ni catalysts supported on palladium give the most promising results during hydrogen production (Yoshida et al., 2009). Such metalsupported catalysts have shown to provide more hydrogen/CO ratio when compared to unsupported catalysts. The supported catalysts support enhanced catalytic activity, enhanced stability, and larger active surface area for the catalyst to function. Any support gives porosity that gives increased contact with reactants. Moreover, the nature of contact between the support element and the catalyst, and the bond between them determines the reaction rate during hydrogen production. Studies have shown that the addition of $\mathrm{Mg}, \mathrm{Co}, \mathrm{Zn}$ elements increases Ni-based catalysts ( $\mathrm{Zhu}$ et al., 2011). Also, $\mathrm{ZrO}_{2}$ is an unbound or nonsupported catalyst that leads to increased efficiency for hydrogen production via an autothermal oxidation reaction (Jeong et al., 2006). In addition to these catalysts, bifunctional catalysts can also be used to help improve the reaction rate of hydrogen production to increase the hydrogen yield. The proposed structure of such bifunctional catalysts has been shown in Figure 10.

Of all the catalysts studied for the gasification process, alkali metals were the first to be researched (Francke et al., 2018). Unsupported catalysts based on natural minerals, noble gas, and synthetically available triggers have also been studied and developed for hydrogen production via direct biomass gasification (Al-Rahbi and Williams, 2017; Yang et al., 2019). These catalysts can undergo rapid action, decrease the amount of tar production, and increase total hydrogen gas. Sometimes even microorganisms are used that are chemically active. Such microbes tend to generate electricity by producing electrons. When these organisms are used as "catalysts," the process becomes very economical and highly efficient. Electrochemically active microbes are used in a cell with protons, electrons, and other chemical substances to ease the reaction. Because of the coupling of such components, direct production of hydrogen occurs (Kim et al., 2017; Ma et al., 2021). The dissolved organic components get oxidized, and the protons are reduced to give hydrogen.

Metals like nickel, iron, and cobalt have also been used in methane pyrolysis reactions without the need for a supporting structure (Srilatha et al., 2017). This is because of their enhanced activity, temperature conditions, and ability to produce solid carbon as the byproduct. These metal catalysts also allow solubility and diffusion of carbons through catalysts' surface. Of all the catalysts mentioned above, $\mathrm{Ni}$ has the highest activity and least toxicity for this reaction (Ouyang et al., 2019). However, these elements undergo deactivation at very high temperatures $\left(>600^{\circ} \mathrm{C}\right)$. In the case of unsupported catalysts, the catalytic 


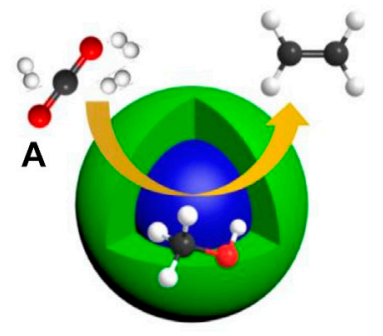

Core-shell

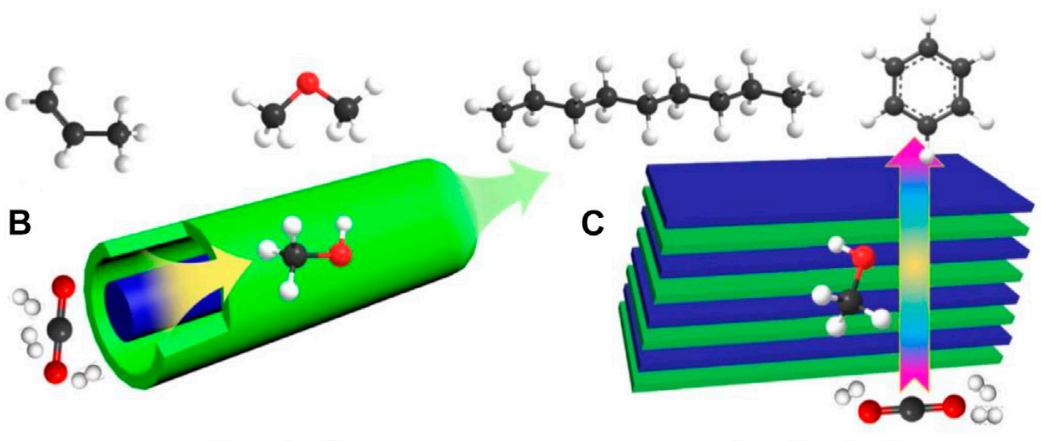

Lamellar structure

FIGURE 10 | Proposed structures of bifunctional catalysts. Adapted with permission from reference Ye et al. (2019), copyright@2019 (Nature).

activity during aqueous phase reforming was noted to be $(\mathrm{He}$ et al., 2013):

$$
\begin{aligned}
\text { Platinum } & =\text { nickel }>\text { ruthenium }>\text { rhodium } \\
& =\text { palladium }>\text { iridium }
\end{aligned}
$$

Of all the catalysts, $\mathrm{Ni}$ has shown to display the lowest reformation of the reactants and allows for efficient hydrogen production. Alkali metals derived from acids have also shown efficiency during the catalytic process - like the alkali metal salts derived from weak acids. These include potassium carbonate, potassium sulfide, sodium carbonate, and sodium sulfide. During these reactions, lower temperatures are better preferred, that is, between 700 and $925^{\circ} \mathrm{C}$ (Mei Wu et al., 2014). These catalysts are added to the gasifier present on coal or char. These catalysts, however, are not quickly recovered after the gasification process. Moreover, elements present in the catalyst, like sulfur, can sometimes poison the catalysts during the reaction.

\section{Metal Oxide Supported Catalysts}

Various transition metals supported on oxides are also used as catalysts in TMD reactions (Shen and Lua, 2015a). These include metals like $\mathrm{Ni}, \mathrm{Fe}$, and $\mathrm{Co}$, and others. Various studies (Khan et al., 2016; Abdullah et al., 2017; Chen et al., 2020b; Baig et al., 2021) have shown the effects of different metal oxide supported catalysts like $\mathrm{La}_{2} \mathrm{O}_{3}, \mathrm{ZiO}_{2}, \mathrm{Al}_{2} \mathrm{O}_{3}, \mathrm{SiO}_{2}$, and $\mathrm{TiO}_{2}$ involved in producing hydrogen (Kim et al., 2011; El Hakim et al., 2021). In a study by Ibrahim et al., it was found that $\mathrm{Fe}$ over $\mathrm{La}_{2} \mathrm{O}_{3}$ showed promising results for TMD at temperatures ranged between 500 and $700^{\circ} \mathrm{C}$. Another study by Shen and colleagues on $\mathrm{Ni}$ supported on $\mathrm{TiO}_{2}$ revealed that this catalyst showed higher stability and expressed a high hydrogen production rate as compared to a catalyst unsupported by $\mathrm{Ni}$ (Shen and Lua, 2015b). Of all studies on metal oxides supported on carbon substances, silica-based materials serve as better catalysts because of their increased surface area. They also possess enhanced thermal stability, changeable pore size, and increased diffusion ability (Di Michele et al., 2019). This makes them an ideal candidate to be used in metal oxide supported catalysts for hydrogen production.
The behavior of metal oxide supported catalysts has shown to be far more convenient and useful in POM reactions. Ni-based oxide supported catalysts like the ones kept on $\mathrm{Al}_{2} \mathrm{O}_{3}, \mathrm{La}_{2} \mathrm{O}_{3}$, $\mathrm{ZrO}_{2}, \mathrm{CeO}_{2}$, etc. are developed through solid-state reaction and wet impregnation. These catalysts, however, are easily deactivated because of the rapid deposition of carbon. Moreover, contamination because of $\mathrm{Ni}$ nanoparticles may also result in their deactivation. However, the metal catalysts that are supported on ceria and alumina have shown to be very promising. This is because of the large surface area of the $\mathrm{Ni}$ nanoparticles on the alumina surface and the available spots in ceria structures that allows for the direct adsorption on those sites (Singha et al., 2017).

On the contrary, catalysts attached to Mg-based structures that rapidly undergo deactivation due to the creation of $\mathrm{NiO} / \mathrm{MgO}$ irreducible complexes in the solution. Metal oxides like $\mathrm{La}_{2} \mathrm{O}_{3}$ allow for decreased carbon formation because of the high scattering of Ni nanoparticles (Kumar et al., 2019). Moreover, these structures also cause lanthanum oxycarbonate development that causes further gasification of carbon structures. $\mathrm{ZrO}_{2}$ also plays an essential role in serving as the support structure for metal catalysts. However, these oxides reduce the oxygen presence that is essential in POM reaction (Hongloi et al., 2019).

Among the metal oxide supported catalysts that are well studied, $\mathrm{Ni} / \mathrm{Al}_{2} \mathrm{O}_{3}$ has gained wide popularity because of its cheap availability and high stability (Alvarez-Galvan et al., 2019). Other metal oxide supports include $\mathrm{MgO}, \mathrm{SiO}_{2}, \mathrm{TiO}_{2}$, $\mathrm{CeO}_{2}$ etc. Furthermore, $\mathrm{Al}_{2} \mathrm{O}_{3}$ disallows catalyst frittage and increases the overall mechanical stability of the catalysts. Beyond $973 \mathrm{~K}$, the sensitivity of the $\mathrm{Al}_{2} \mathrm{O}_{3}$ based metal oxide catalysts also increases. Hence, any changes in $\mathrm{Al}_{2} \mathrm{O}_{3}$ support create catalysts that directly affect the catalysts (Koh et al., 2007). In some instances, transition metal oxides like $\mathrm{CeO}_{2}, \mathrm{ZrO}_{2}$, and $\mathrm{Cr}_{2} \mathrm{O}_{3}$ are used along with alumina components (Silva et al., 2012). However, oxygenates rapidly undergo dehydration and give ethylene, resulting in carbon deposition and catalyst deactivation (Ali et al., 2016; Rogers et al., 2016). Studies have shown that $\mathrm{CeO}_{2}$ support increases the stability and activity of Ni-based catalysts (Arora and Prasad, 2016). Moreover, the addition of $\mathrm{Ce}$ to $\mathrm{ZrO}_{2}$ results in strong interaction between the individual substances present on the 
catalyst. Also, Ce causes enhanced storage capacity of oxygen and allows for the synthesis of transferrable oxygen during the reaction process. Hyun Seog Toh and colleagues studied multiple metal oxide supported catalysts (like $\mathrm{MgO}, \mathrm{Ce}-\mathrm{ZrO}_{2}$, $\mathrm{MgAl}_{2} \mathrm{O}_{4}$ ) however, $\mathrm{Ni}$ catalysts supported on $\mathrm{MgAl}_{2} \mathrm{O}_{3}$ showed the maximum efficiency and stability (Roh et al., 2001; Shang et al., 2017).

Metal oxides of alkaline earth metals are favorable for gasification reaction because they permit reformation reactions (Nikolaidis and Poullikkas, 2017). When metal catalysts like $\mathrm{Cu}$ catalysts are introduced into the reaction, additional elements like promoters are also used. This is to decrease the amount of nonrequired products (like the soot and tar) and increase the total hydrogen produced. The metal oxides, including the oxides of transition metals, are alkali earth metals are often introduced as the promoters during the reaction (Gupta et al., 2011; Qu et al., 2020).

The $\mathrm{ZnO} / \mathrm{Zn}$ redox pairs have shown to have better superiority among other metal oxide supported catalysts during hydrogen production via this reaction (Steinfeld, 2002). However, this metal oxide pair is not feasible for the large-scale production of hydrogen. Moreover, efficient separation of the products poses a challenge (Koepf et al., 2016). Hence, because of the shortcomings, $\mathrm{CeO}_{2}$ is a better candidate for water splitting reaction and hydrogen production (Gokon et al., 2013). However, these catalysts function at high temperatures of $1700-3000 \mathrm{~K}$. Other metal oxide supported catalysts include the redox pairs of $\mathrm{Mn}_{2} \mathrm{O}_{3} / \mathrm{MnO}, \mathrm{SnO}_{2} / \mathrm{SnO}, \mathrm{Fe}_{2} \mathrm{O}_{4} / \mathrm{Fe}$, etc. The enhanced surface area of platinum supported on $\mathrm{Al}_{2} \mathrm{O}_{3}$ and $\mathrm{ZrO}_{2}$ also shows very high activity. However, these catalysts exhibit rapid deactivation too. Platinum catalyst supported on $\mathrm{TiO}_{2}$ also show very high stability. However, they too get deactivated when used for prolonged durations.

Fe catalysts supported on other metal oxides like $\mathrm{Al}_{2} \mathrm{O}_{3}$ based catalysts have been studied for this reaction and have shown promising results (Zhou et al., 2016). When such catalysts are used, they offer in situ catalysis during methane pyrolysis. This was seen in the work put forward by Yeheskel and coworkers (Yeheskel and Epstein, 2011). The authors discussed when $\mathrm{Fe}(\mathrm{CO})_{5}$ and $\mathrm{Fe}\left(\mathrm{C}_{2} \mathrm{H}_{5}\right)_{2}$ are decomposed. Fe clusters are produced during the pyrolysis reaction. Besides, various other gases are also produced as by-products. These gases produced, however, undergo further decontamination steps.

Metal oxide supports like $\mathrm{Al}_{2} \mathrm{O}_{3}$ and $\mathrm{Fe}_{3} \mathrm{O}_{4}$ have shown to be very efficient in hydrogen synthesis via aqueous steam reforming (Gumina et al., 2019). Valenzuela and colleagues were the first teams who developed this process for hydrogen production (Valenzuela et al., 2006). They employed Pt catalysts supported on $\mathrm{Al}_{2} \mathrm{O}_{3}$. High activity of the catalyst structure and large hydrogen production was noted during the reaction. In another study, the catalytic activity of $\mathrm{CeO}_{2}-\mathrm{ZrO}_{2}$ and $\mathrm{CeO}_{2}-\mathrm{TiO}_{2}$ was studied (Chen et al., 2017a). It was noted that both sets of catalysts showed high activity and efficiency. Moreover, these catalysts, including $\mathrm{Pt}-\mathrm{Al}_{2} \mathrm{O}_{3}$, were observed to show high catalytic activity and were recyclable.

Among the metal oxide supported catalysts, $\mathrm{K}_{2} \mathrm{CO}_{3}$ has shown high catalytic activity during the gasification reaction compared to $\mathrm{Ni}$ catalysts supported on metal oxides. It has been observed that hydrogen production is increased two times when $\mathrm{K}_{2} \mathrm{CO}_{3}$ is used as a catalyst ( $\mathrm{Li}$ et al., 2010). This could be because of the high and uniform solubility of the catalyst in the reaction mixture. Other catalysts like $\mathrm{SiO}_{2}, \mathrm{KAlSiO}_{4}, \mathrm{NiO}$, and $\mathrm{KAlSi}_{3} \mathrm{O}_{8}$ have been shown to undergo rapid deactivation owing to large carbon deposits on their surface. Other metal oxide-supported catalysts like $\mathrm{ZnO}$ were shown to exhibit quick activity in contrast to $\mathrm{SnO}_{2}$ catalysts; the hydrogen yield was also enhanced.

\section{Noble Metal-Based Catalysts}

Noble metal catalysts like ruthenium and rhodium used in the SMR process exhibit increased activity and high stability (Chen et al., 2017b). Other noble metals like platinum and iridium show enhanced electrocatalytic activity and can be attached to other elements to give better catalytic activity (Swain et al., 2018). However, there are a few drawbacks to these catalysts including their high cost of production and instability (Digraskar et al., 2019). These can be overcome by reducing the size of the noble metals attached to porous carbon structure. This increases the overall efficiency of catalysts. Furthermore, they can be attached to other transition metals to enhance the catalyst's activity ( $\mathrm{Li}$ et al., 2019). These steps can be incorporated at an industrial level to reduce their overall cost of production.

Noble metals like palladium, rhodium, platinum, iridium also serve as noble metal-based catalysts in POM reaction (Figen and Baykara, 2018; Ma et al., 2019). Studies have shown the reducing nature of noble metals like ruthenium that results in lanthanide oxide-supported ruthenium structures that are used catalysts in POM (Lian et al., 2018). Owing to the enhanced performance of noble metal catalysts, these catalysts have gained a great deal of attention from the scientific community. In a study by AlvarezGalvan and colleagues, it was discovered that rhodium, when used as the supporting material of metals like $\mathrm{Ni}$, promotes the further reduction of the catalyst, thereby improving the overall catalytic activity during POM (Alvarez-Galvan et al., 2019). It has been noted that the catalytic activity of ruthenium-based catalysts is significantly greater at greater flow rates than Ni-based catalysts (Wysocka et al., 2019). However, the method used to prepare the catalyst and the supporting structure also determines their activity (Horn and Schlögl, 2015).

Noble metal-based catalysts show a better and bigger ratio of hydrogen and $\mathrm{CO}$ than metal oxide supported catalysts. For instance, when present in the Ni-based catalyst, palladium disallows the oxidation of catalyst and maintains its reduced state. The bigger the noble metal clusters of the catalyst, the stronger the interaction and, hence, the more stable the catalyst's overall structure (Mosinska et al., 2020). This was seen in the study by Keiichi Tomishige and coworkers. The authors reported that $\mathrm{Ni}$ and Pt catalysts restrict the formation of carbon structures on the catalysts. In another study, Antonio Vita and coworkers studied $\mathrm{CeO}_{2}$ based catalysts attached to metals like rhodium, platinum, nickel used in autothermal reforming reactions (Vita et al., 2015). Of all the catalysts studied by the authors, catalysts based on $\mathrm{CeO}_{2}$ showed the least stability, while catalysts based on $\mathrm{Ru}$ showed very high methane conversion rates and high hydrogen yields. 
TABLE 6 | Various catalysts used in hydrogen production by methane pyrolysis.
Catalyst type

Metal catalyst

Metal supported catalysts

Non supported catalysts

Metal oxide supported catalysts

Noble metal supported catalysts

\section{Examples}

$\mathrm{Ni}, \mathrm{Fe}, \mathrm{Co}$

NPs, MOFs, Carbon NMs

Cellulose, ionic liquids

$\mathrm{La}_{2} \mathrm{O}_{3}, \mathrm{ZiO}_{2}, \mathrm{Al}_{2} \mathrm{O}_{3}, \mathrm{SiO}_{2}$

$\mathrm{Pt}, \mathrm{Ir}, \mathrm{Pd}, \mathrm{Rh}, \mathrm{Ce}$
Rhodium based catalysts are the most popularly used noble metal-based catalysts for the gasification process. This is because of the enhanced selectivity and cost ineffectiveness. However, these are relatively quite expensive. Regardless, noble metal-based catalysts, including rhodium, palladium, and platinum, among others, have been found to have enhanced activity, stability, and increased resistance to deposition of carbon on the catalysts' surface (Hakouk et al., 2018). Among the noble metal-based catalysts, platinum has shown the maximum efficiency for the water-splitting reaction. These elements act as electron magnets and decrease the potential for hydrogen production (Wang et al., 2015). When supported on $\mathrm{TiO}_{2}$, electron transfers occur from $\mathrm{TiO}_{2}$ to platinum. On the contrary, noble metals like rhodium do not show very efficiency during this reaction, and hence the amount of hydrogen production is lowered (Jana et al., 2010).

Like the metal-based catalysts, the noble metal-based catalysts show better activity and stability than metal catalysts without supporting materials. This was seen in the work put forward by Pudukudy and colleagues (Pudukudy et al., 2018). They developed techniques that could synthesize hydrogen devoid of carbon-based co-products. They used ceria along with platinumbased nickel catalysts. The authors noted that there were no separate peaks in regards to platinum observed. This meant that the addition of the noble metal platinum permitted good dispersion on the catalyst surface. Moreover, the overall activity was noted to be highly efficient in the addition of platinum. Hence, such noble metal-based catalysts are also considered to increase the catalyst's overall activity. Various kinds of catalysts that are used in hydrogen production by methane pyrolysis are shown in Table 6.

A few years after the first APR activity for hydrogen production was recorded, Erbatur and colleagues then investigated APR using various catalysts. They noted that platinum displayed the best catalytic efficiency and activity during the reaction (Meryemoglu et al., 2010). After platinum, ruthenium, and palladium recorded the highest activity and catalytic efficiency. This could be because of the availability of strong minerals that are essential for hydrolytic activity. Moreover, the mineral acids result in the drainage of the noble metals into the solution. This thus limits the recycling of the catalysts. However, their high expense is the sole disadvantage of using noble metal-based catalysts.

Ruthenium based catalysts have shown five to ten times better activity than other noble metal-based catalysts (Molino et al., 2018). The only drawback is the high rate of deactivation of ruthenium-based catalysts because of the carbon supporting material often used along with this catalyst. During the reaction, carbon is also shown to be utilized, which reduces ruthenium activity. Other elements, like platinum and palladium, have also shown promising catalytic activity. They can overcome the drawbacks posed by nickel-based catalysts. Their only drawback is their expensive availability. Tomishige and coworkers discovered that the order of catalyst activity to be (Tomishige et al., 2004):

\section{rhodium $>$ palladium $>$ platinum $>$ nickel $=$ ruthenium}

Therefore, among most catalysts, noble metal-based catalysts show the maximum activity during coal gasification reaction. Many studies have carried out to understand the catalytic process of the various techniques. Various kinds of catalysts have been used for hydrogen production via the TMD process. Some of these are comprehensively discussed below in Table 7 .

\section{CATALYTIC DEACTIVATION}

We have discussed a number of catalysts above. Though the metal catalysts and metal-based catalysts show an enhanced conversion during the TMD reaction, its rates of deactivation is also high. The biggest challenge that causes deactivation is the development of metal carbide structures over the catalysts surface. Also, sulfur content also poses a significant concern during the process. These sulfur components also cause poisoning of the catalysts. Unlike the carbon-based catalysts, metal-based catalysts cannot absorb these sulfur components from the feedstock. This limited life of the catalyst upon deactivation couple with lowered hydrogen to carbon ratio slows the industrial applicability of such catalysts. This therefore causes the development of low quality fuels that possess low heating value when compared to fossil fuels (Chew and Bhatia, 2009; Alaba et al., 2016).

Catalyst regeneration, in turn, would be done by burning off carbon deposited that affects the entire life of the catalysts (Cao and $\mathrm{Yu}, 2016)$. When carbon-based catalysts are used in the reaction, there are many advantages like more flexibility in the reaction, and lack of poisoning due to other elements. Moreover, these catalysts display lower resistance to temperature changes. Figure 11 displays the general pathway followed for catalyst selection during TMD process.

The main reason behind any catalyst's deactivation is the deposition of solid carbon/coke on the catalyst's surface. This carbon lowers the activity function and hence hampers the functionality of the catalyst. Studies have suggested the Nibased catalysts show high efficiency during TMD. The reaction is carried out at temperatures ranged between 500 and $600^{\circ} \mathrm{C}$. This temperature range is not as high as required to attain equilibrium. However, at increased temperature ranges, $\mathrm{Ni}$ catalysts undergo rapid deactivation. Hence, sometimes $\mathrm{Fe}$ is used instead of $\mathrm{Ni}$. This is because Fe unlike Ni can stand through high temperatures without undergoing deactivation. Moreover Fe is cheaper than Ni (Qian et al., 2020).

For TMD to proceed efficiently and for the catalysts to remain active for prolonged durations, better alternatives for catalysts have to be studied. Another challenge during TMD is the poisoning of the catalysts because of sulfur compounds. These poisons also deactivate the catalysts and hinder the reaction 
TABLE 7 | Catalysts used for hydrogen production via TMD process.

\begin{tabular}{|c|c|c|c|c|c|c|}
\hline Catalyst & Catalyst type & $\begin{array}{c}\text { Methane } \\
\text { conversion } \\
(\%)\end{array}$ & $\begin{array}{l}\text { Hydrogen } \\
\text { yield }\end{array}$ & Temp ( $\left.{ }^{\circ} \mathrm{C}\right)$ & Methane flow rate & References \\
\hline $\mathrm{NiO} / \mathrm{Al}_{2} \mathrm{O}_{3}-\mathrm{SiO}_{2}$ & Metal oxide catalyst & $\sim 40$ & $1,730(\mathrm{~mol} \mathrm{H} / \mathrm{mol} \mathrm{Ni})$ & 550 & $30 \mathrm{cc} / \mathrm{min}$ & Ashok et al. (2008a) \\
\hline Activated carbons & Non supported catalyst & - & - & 900 & $20 \mathrm{ml} / \mathrm{min}$ & Ashok et al. (2008c) \\
\hline $\mathrm{Fe}$ & Non supported metal catalyst & $\sim 80$ & - & 800 & $27.5 \mathrm{~N} \mathrm{~cm}^{3} / \mathrm{min}$ & Cunha et al. (2008) \\
\hline Co & Non supported metal catalyst & $\sim 80$ & - & 800 & $27.5 \mathrm{~N} \mathrm{~cm}^{3} / \mathrm{min}$ & Cunha et al. (2008) \\
\hline $\mathrm{Ni}$ & Non supported metal catalyst & $\sim 80$ & - & 800 & $27.5 \mathrm{~N} \mathrm{~cm}^{3} / \mathrm{min}$ & Cunha et al. (2008) \\
\hline FeMo/MgO & Metal oxide supported catalyst & 87 & - & 900 & $50 \mathrm{ml} / \mathrm{min}$ & Pinilla et al. (2011) \\
\hline $\mathrm{Ni} / \mathrm{SiO}_{2}$ & Metal oxide supported catalyst & 35 & $3.4\left(\mathrm{~mol} \mathrm{H}_{2} / \mathrm{mol} \mathrm{CH}_{4}\right)$ & 550 & - & Zhang and Amiridis, (1998) \\
\hline $\mathrm{Ni} / \mathrm{SiO}_{2}-\mathrm{Al}_{2} \mathrm{O}_{3}$ & Metal oxide supported catalyst & $\sim 80$ & - & 700 & $20 \mathrm{~cm}^{3} / \mathrm{min}$ & Suelves et al. (2005) \\
\hline $\mathrm{Ni} / \mathrm{MgO}$ & Metal oxide supported catalyst & $35-40$ & - & 550 & $60 \mathrm{~N} \mathrm{~cm}^{3} / \mathrm{min}$ & Bonura et al. (2006) \\
\hline $\mathrm{Ni} / \mathrm{SiO}_{2}$ & Non supported catalyst & $35-40$ & - & 550 & $60 \mathrm{~N} \mathrm{~cm}^{3} / \mathrm{min}$ & Bonura et al. (2006) \\
\hline $\mathrm{Ni} / \mathrm{Cu}-\mathrm{Nb}_{2} \mathrm{O}_{5}$ & Metal supported catalyst & $\sim 45$ & $7,274 \mathrm{~mol} \mathrm{H} / 2 \mathrm{~mol} \mathrm{Ni}$ & 600 & $40 \mathrm{~cm}^{3} / \mathrm{min}$ & Li et al. (2004) \\
\hline $\mathrm{Ni} / \mathrm{Cu}$-alumina & Metal supported catalyst & 70 & - & 750 & $68 \mathrm{~cm}^{3} / \mathrm{min}$ & Li et al. (2000) \\
\hline $\mathrm{Ni} / \mathrm{Cu}-\mathrm{Si}$ & Metal supported catalyst & $\sim 80$ & - & 700 & $20 \mathrm{~cm}^{3} / \mathrm{min}$ & Lázaro et al. (2007) \\
\hline $\mathrm{Ni} / \mathrm{Cu}-\mathrm{MgO}$ & Metal oxide supported catalyst & 45 & - & 700 & $60 \mathrm{~cm}^{3} / \mathrm{min}$ & Wang and Baker, (2004) \\
\hline $\mathrm{Ni} / \mathrm{Cu}-\mathrm{Al}$ & Metal supported catalyst & 65 & - & 700 & $20 \mathrm{~cm}^{3} / \mathrm{min}$ & Suelves et al. (2006) \\
\hline $\mathrm{Ni} / \mathrm{Cu}-\mathrm{Mg}$ & Metal supported catalyst & $\sim 67$ & - & 700 & $20 \mathrm{~cm}^{3} / \mathrm{min}$ & Moliner et al. (2008) \\
\hline $\mathrm{Fe} / \mathrm{MgO}$ & Metal oxide supported catalyst & $\sim 87$ & - & 800 & $50 \mathrm{ml} / \mathrm{min}$ & Pinilla et al. (2011) \\
\hline $\mathrm{NiCuAl}$ & Metal supported catalyst & 31.2 & - & 700 & $150 \mathrm{~N} \mathrm{~cm}^{3} \mathrm{~min}^{-1}$ & Suelves et al. (2009) \\
\hline $\mathrm{Co} / \mathrm{Al}_{2} \mathrm{O}_{3}$ & Noble metal supported catalyst & $\sim 22$ & - & 700 & $35 \mathrm{~cm}^{3} / \mathrm{min}$ & Nuernberg et al. (2008) \\
\hline $\mathrm{Fe} / \mathrm{Al}_{2} \mathrm{O}_{3}$ & Metal oxide supported catalyst & 7.9 & - & 625 & - & Avdeeva et al. (2002) \\
\hline $\mathrm{NiO}-\mathrm{CuO}$ & Non supported catalyst & 85 & - & 750 & $25 \mathrm{ml} / \mathrm{min}$ & Lua and Wang, (2013) \\
\hline $\mathrm{Ni} / \mathrm{SiO}_{2}$ & Non supported catalyst & 88 & $\sim 89 \%$ & 750 & $30 \mathrm{ml} / \mathrm{min}$ & Saraswat and Pant, (2013) \\
\hline $\mathrm{Ni}-\mathrm{Mo} / \mathrm{Al}_{2} \mathrm{O}_{3}$ & Metal oxide supported catalyst & $\sim 80$ & $\sim 88 \%$ & 750 & - & Awadallah et al. (2013) \\
\hline $\mathrm{Al}_{2} \mathrm{O}_{3}-\mathrm{TiO}_{2}$ & Metal oxide supported catalyst & $\sim 70$ & $59 \%$ & 700 & 50 sccm & Awadallah et al. (2014) \\
\hline $\mathrm{Ni}-\mathrm{Co} / \mathrm{Al}_{2} \mathrm{O}_{3}-\mathrm{MgO}$ & Metal oxide supported catalyst & $\sim 80$ & - & 800 & $500 \mathrm{ml} / \mathrm{min}$ & Karaismailoglu et al. (2019) \\
\hline $\mathrm{Ni}$ & Non supported catalyst & 53 & - & 700 & $70 \mathrm{ml} / \mathrm{min}$ & Li et al. (2017) \\
\hline Magnesium-NiO & Metal oxide supported catalyst & 82 & $1.8 \%$ & 800 & $30 \mathrm{sccm}$ & Al-Fatesh et al. (2020) \\
\hline $\mathrm{Ni}_{3} \mathrm{Si}_{2} \mathrm{O}_{5}(\mathrm{OH})_{4}$ & Non supported catalyst & 85 & - & 800 & - & Zhang et al. (2019b) \\
\hline $\mathrm{NiO}-\mathrm{MgO}-\mathrm{Al}_{2} \mathrm{O}_{3}$ & Metal oxide supported catalyst & 91 & - & 800 & - & Chai et al. (2017) \\
\hline Ni-La@KCC-1 & Metal supported catalyst & 96 & - & 750 & $100 \mathrm{ml} / \mathrm{min}$ & Abdulrasheed et al. (2020) \\
\hline $\mathrm{Ni} / \mathrm{Ce}-\mathrm{ZnAl} 2 \mathrm{O} 4$ & Noble metal supported catalyst & 82 & $92 \%$ & 800 & $10^{\circ} \mathrm{C} / \mathrm{min}$ & Movasati et al. (2017) \\
\hline $\begin{array}{l}\text { Ni/alumina- } \\
\text { zirconia }\end{array}$ & Metal supported catalyst & 90 & $72 \%$ & 800 & $32.5 \mathrm{ml} / \mathrm{min}$ & Fakeeha et al. (2020) \\
\hline $\mathrm{Ni} / \mathrm{SiO}_{2} \mathrm{Al}_{2} \mathrm{O}_{3}$ & Metal oxide supported catalyst & 100 & - & 900 & $25 \mathrm{ml} / \mathrm{min}$ & Ali et al. (2016) \\
\hline $\mathrm{Ni} / \mathrm{MgAl}_{2} \mathrm{O}_{4}$ & Metal oxide supported catalyst & 75 & - & 850 & - & Katheria et al. (2016) \\
\hline $\mathrm{Ni} / \mathrm{Ni}_{2} \mathrm{Al}_{2} \mathrm{O}_{5}$ & Metal oxide supported catalyst & 82 & $\sim 20 \%$ & $\sim 650$ & - & Rogers et al. (2016) \\
\hline $\mathrm{Ru} / \mathrm{ZnLaAlO}{ }_{4}$ & Noble metal supported catalyst & 72 & $99.8 \%$ & 800 & $50 \mathrm{~N} \mathrm{ml} / \mathrm{min}$ & Khani et al. (2016) \\
\hline $\mathrm{Ni} / \mathrm{CeO}_{2} / \mathrm{Al}_{2} \mathrm{O}_{3}$ & Noble metal supported catalyst & $\sim 94$ & $42.52 \%$ & $\sim 900$ & - & Peng et al. (2017) \\
\hline $\mathrm{Ni} / \mathrm{Ru} / \gamma-\mathrm{Al}_{2} \mathrm{O}_{3}$ & Noble metal supported catalyst & 80 & - & $\sim 650$ & - & Calzada Hernandez et al. (2020) \\
\hline $\mathrm{Ni} / \mathrm{Pt}-\gamma-\mathrm{Al}_{2} \mathrm{O}_{3}$ & Noble metal supported catalyst & 80 & - & $\sim 700$ & - & De Vlieger et al. (2012) \\
\hline
\end{tabular}

progression. Furthermore, the metal-support made available to the catalyst also plays a significant role in catalytic deactivation. If the support and metal bond are not strong, the metal counterpart's detachment can also cause the catalyst's deactivation. When the metals get detached, they tend to get localized in nanotubes. This causes the deactivation of the catalyst over a while. When the bonds between metal and support are more robust, the catalyst deactivation is slowed; however, catalyst deactivation follows despite the prevailing circumstances.

\section{CATALYST REGENERATION}

A catalyst cannot maintain its functionality and selectivity for prolonged durations. Their activity reduces with time, which results in its deactivation. This deactivation may sometimes occur rapidly and sometimes may take months (like sulfur poisoning cases). Sometimes, catalytic deactivation can also take years, like in ethylene hydrogenation and ammonia production. Catalytic poisoning, coking, and restructuring of the catalyst are responsible for the catalytic deactivation. After catalyst deactivation, catalysts can be regenerated using oxygen (Saad and Williams, 2016; Gao et al., 2019; Vasiliades et al., 2020). The significant methods employed for catalyst regeneration include combustion and gasification. Oxygen is considered during regeneration via combustion, while steam is used during regeneration via steam. The following two stoichiometric reactions highlight the regeneration of catalysts (Srilatha et al., 2017):
$\mathrm{C}+\mathrm{O}_{2} \rightarrow \mathrm{CO}_{2}$
$\Delta \mathrm{H}_{1073}=-394.7 \mathrm{~kJ} / \mathrm{mol}$ 


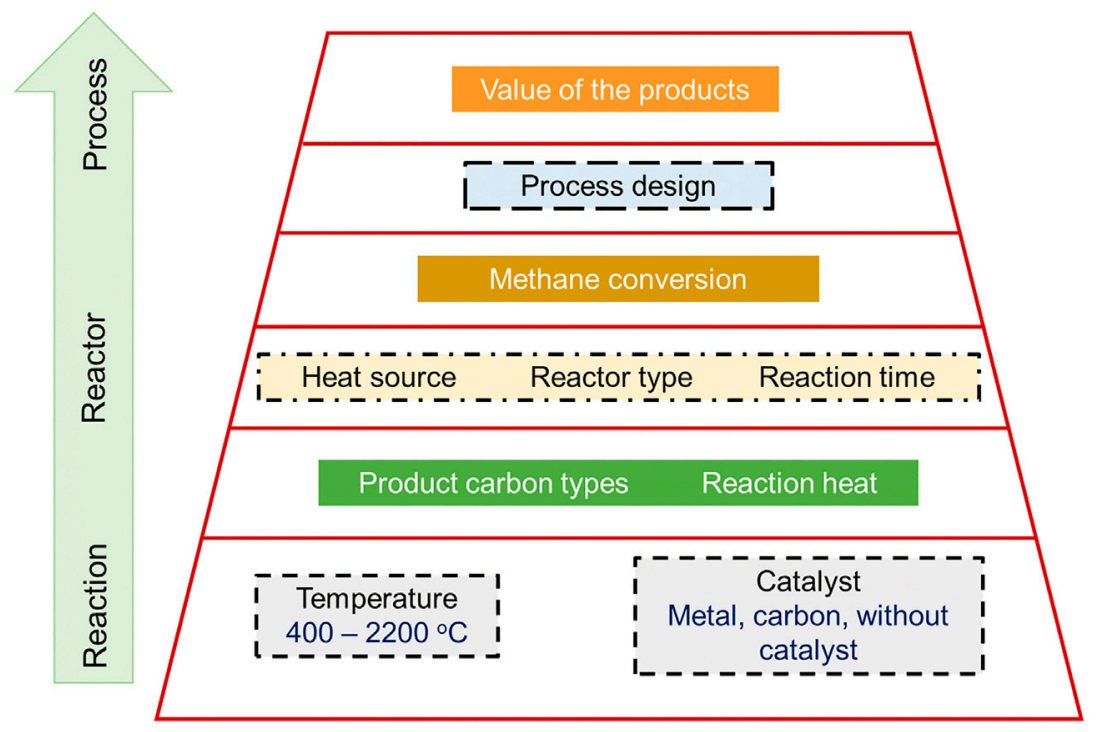

FIGURE 11 | Catalytic decomposition pathway during TMD process. Adapted with permission from reference Hasnan et al. (2020b), copyright@2020 (Springer).

$$
\begin{array}{ll}
\mathrm{C}+\mathrm{H}_{2} \mathrm{O} \rightarrow \mathrm{CO}+\mathrm{H}_{2} & \Delta \mathrm{H}_{1073}=135.9 \mathrm{~kJ} / \mathrm{mol} \\
\mathrm{C}+\mathrm{CO}_{2} \rightarrow 2 \mathrm{CO} & \Delta \mathrm{H}_{1073}=174.5 \mathrm{~kJ} / \mathrm{mol}
\end{array}
$$

Catalytic activation is done by removing the carbon deposition from the catalyst's matrix sites, which increases the total surface area of the catalysts for further reactions. However, during catalyst regeneration, purification steps became indispensable to get pure hydrogen as the end product. This is because regeneration steps result in the production of $\mathrm{CO}_{\mathrm{x}}$, which makes the purification step necessary. Some catalysts, however, do not require regeneration steps and consideration activity. Examples of such catalysts include nickel supported on $\mathrm{ZrO}_{2}$ and $\mathrm{Al}_{2} \mathrm{O}_{3}$ (Shang et al., 2017). Over time, these catalysts have physically blocked the reactor and cause a drop in pressure throughout the catalyst bed. Hence, catalyst regeneration becomes a necessary step to avoid inefficiency in the catalytic activity during the thermal decomposition of methane for hydrogen production.

Catalytic regeneration has been observed in the works put forward by Amin and colleagues (Amin et al., 2012). They introduced three different Ni-based catalysts in a fluidized bed reactor at a temperature above $500^{\circ} \mathrm{C}$. They used oxygen as the activating agent for the reaction to proceed. The authors noted that carbon was removed entirely on all the catalysts studied. In another similar study, Amjed and coworkers studied activated carbon during TMD above $900^{\circ} \mathrm{C}$ (AlHassani et al., 2014). The authors developed models to understand the functional surface area in the catalyst and the volume of pores. This kinetics was designed to understand the process of catalytic deactivation better. Moreover, it was also observed that rapid deterioration of the catalysts occurred at very high temperatures due to catalyst frittage or weakening.

\section{CONCLUSION AND FUTURE PERSPECTIVE}

Production of hydrogen devoid of $\mathrm{CO}_{\mathrm{x}}$ components is particularly challenging; however, it's essential for ecofriendly measures. In this review, we have discussed the various kinds of catalysts available (including metal-based catalysts, noble-metal-based catalysts, non-supported catalysts, metal-oxide-based catalysts) and the mechanism of different processes available for hydrogen production. Though the thermocatalytic decomposition of methane and the catalysts involved have been thoroughly studied, factors like optimization of the catalysts, cost of the process, and the necessity of regeneration of catalysts still require in-depth exploration and analysis. Moreover, despite alternative options being available, the dependence on fossil fuels and their derivatives will continue even in the future. These options, however, do not limit emissions of greenhouse gases. Hence additional steps can be added in the process such that carbon black is produced. These compounds are valuable in the market; therefore, the overall expense of the process gets reduced. Other external factors, like supporting conditions and the kind of catalysts used, also influence the cost and carbon type formed as a by-product.

Studies show that thermocatalytic decomposition of methane for hydrogen production is also affected by the temperature at which reactions proceed and even the type of catalysts used. For instance, Fe-based catalysts showed high activity at high-temperature conditions. Nickel-copper alloy catalysts show that supported catalysts have better functions as compared to unsupported catalysts. However, their rapid deactivation because of carbon deposition on the catalysts' surface serves as a limiting factor of the process. 
Works of literature have also shown that carbon-based catalysts show enhanced activity because of their cheap availability, stability at high temperatures, and resistance to sulfur poisoning. More research needs to be carried out to study other existing materials that can serve as better catalysts and resist catalytic deactivation during hydrogen production processes. Besides, better-supporting structures will have to be researched so that the resulting catalysts have the higher surface area and increased porosity during catalysis. Promoters can be used to increase the stability of the catalyst. For instance, promoters like $\mathrm{CeO}_{2}$ can improve the stability of active sites and improve the catalysts' functionality. Other structures like mesostructured silica nanoparticles can also be used as a supporting structure because of their vast surface area and changeable pore size. Moreover, they exhibit high resistance to heat and show increased mechanical stability.

So far, $\mathrm{Ni}$ and $\mathrm{Fe}$ are popular options among the available catalysts owing to their inexpensive availability and high activity. More importantly, Ni-based catalysts were found to more reliable than others. However, these catalysts show limitations because of strict temperature

\section{REFERENCES}

Abbas, H. F., and Daud, W. M. A. W. (2010). An Experimental Investigation into the $\mathrm{CO} 2$ Gasification of Deactivated Activated-Carbon Catalyst Used for Methane Decomposition to Produce Hydrogen. Int. J. Hydrogen Energ. 35, 141-150. doi:10.1016/j.ijhydene.2009.10.072

Abbas, H. F., and Daud, W. M. A. W. (2010). Hydrogen Production by Thermocatalytic Decomposition of Methane Using a Fixed Bed Activated Carbon in a Pilot Scale Unit: Apparent Kinetic, Deactivation and Diffusional Limitation Studies. Int. J. Hydrogen Energ. 35, 12268-12276. doi:10.1016/j.ijhydene.2010.08.036

Abbas, H. F., and Wan Daud, W. M. A. (2010). Hydrogen Production by Methane Decomposition: A Review. Int. J. Hydrogen Energ. 35, 1160-1190. doi:10.1016/ j.ijhydene.2009.11.036

Abd Ghani, N. A., Azapour, A., Syed Muhammad, S. A. F. a., Mohamed Ramli, N., Vo, D.-V. N., and Abdullah, B. (2018). Dry Reforming of Methane for Syngas Production over Ni-Co-Supported Al2O3-MgO Catalysts. Appl. Petrochem Res. 8, 263-270. doi:10.1007/s13203-018-0218-5

Abdullah, B., Abd Ghani, N. A., and Vo, D.-V. N. (2017). Recent Advances in Dry Reforming of Methane over Ni-Based Catalysts. J. Clean. Prod. 162, 170-185. doi:10.1016/j.jclepro.2017.05.176

Abdulrasheed, A. A., Jalil, A. A., Hamid, M. Y. S., Siang, T. J., and Abdullah, T. A. T. (2020). Dry Reforming of CH over Stabilized Ni-La@KCC-1 Catalyst: Effects of La Promoter and Optimization Studies Using RSM. J. CO2 Utilization 37, 230-239. doi:10.1016/j.jcou.2019.12.018

Abe, J. O., Popoola, A. P. I., Ajenifuja, E., and Popoola, O. M. (2019). Hydrogen Energy, Economy and Storage: Review and Recommendation. Int. J. Hydrogen Energ. 44, 15072-15086. doi:10.1016/j.ijhydene.2019.04.068

Akubo, K., Nahil, M. A., and Williams, P. T. (2020). Co-pyrolysis-catalytic Steam Reforming of Cellulose/lignin with Polyethylene/polystyrene for the Production of Hydrogen. Waste Dispos. Sustain. Energ. 2, 177-191. doi:10.1007/s42768-020-00047-8

Al-Fatesh, A. S., Kumar, R., Fakeeha, A. H., Kasim, S. O., Khatri, J., Ibrahim, A. A., et al. (2020). Promotional Effect of Magnesium Oxide for a Stable Nickel-Based Catalyst in Dry Reforming of Methane. Sci. Rep. 10. doi:10.1038/s41598-020-70930-1

Al-Hassani, A. A., Abbas, H. F., and Wan Daud, W. M. A. (2014). Production of CO X -free Hydrogen by the thermal Decomposition of Methane over Activated Carbon: Catalyst Deactivation. Int. J. Hydrogen Energ. 39, 14783-14791. doi:10.1016/j.ijhydene.2014.07.031 requirements. Hence these catalysts are linked to other elements like $\mathrm{Cu}$ or $\mathrm{Fe}$ to enhance the stability and overall activity.

\section{AUTHOR CONTRIBUTIONS}

All authors listed have made a substantial, direct, and intellectual contribution to the work and approved it for publication.

\section{FUNDING}

No funding is available for this work.

\section{ACKNOWLEDGMENTS}

GN and MT acknowledge the support provided by Dhofar University through the DURG research grant ref. (DU/AY/ 2020- 21/DURG-004).

Al-Rahbi, A. S., and Williams, P. T. (2017). Hydrogen-rich Syngas Production and Tar Removal from Biomass Gasification Using Sacrificial Tyre Pyrolysis Char. Appl. Energ. 190, 501-509. doi:10.1016/j.apenergy.2016.12.099

Alaba, P. A., Sani, Y. M., Mohammed, I. Y., and Wan Daud, W. M. A. (2016). Insight into Catalyst Deactivation Mechanism and Suppression Techniques in Thermocatalytic Deoxygenation of Bio-Oil over Zeolites. Rev. Chem. Eng. 32. doi:10.1515/revce-2015-0025

Ali, S., Al-Marri, M. J., Abdelmoneim, A. G., Kumar, A., and Khader, M. M. (2016). Catalytic Evaluation of Nickel Nanoparticles in Methane Steam Reforming. Int. J. Hydrogen Energ. 41, 22876-22885. doi:10.1016/ j.ijhydene.2016.08.200

Alvarez-Galvan, C., Melian, M., Ruiz-Matas, L., Eslava, J. L., Navarro, R. M., Ahmadi, M., et al. (2019). Partial Oxidation of Methane to Syngas over NickelBased Catalysts: Influence of Support Type, Addition of Rhodium, and Preparation Method. Front. Chem. 7. doi:10.3389/fchem.2019.00104

Amin, A. M., Croiset, E., Malaibari, Z., and Epling, W. (2012). Hydrogen Production by Methane Cracking Using Ni-Supported Catalysts in a Fluidized Bed. Int. J. Hydrogen Energ. 37, 10690-10701. doi:10.1016/ j.ijhydene.2012.04.082

Anis, S., and Zainal, Z. A. (2011). Tar Reduction in Biomass Producer Gas via Mechanical, Catalytic and thermal Methods: A Review. Amsterdam, Netherlands: Renewable and Sustainable Energy Reviews, Renew. Sustain. Energ. Rev. 15, 2355-2377. doi:10.1016/j.rser.2011.02.018

Arandiyan, H., and Li, J. H. (2012). Catalytic CO2 Reforming of Methane over Perovskite noble Metals. Amr 356-360, 1070-1074. doi:10.4028/ www.scientific.net/AMR.356-360.1070

Arora, S., and Prasad, R. (2016). An Overview on Dry Reforming of Methane: Strategies to Reduce Carbonaceous Deactivation of Catalysts. RSC Adv. 6, 108668-108688. doi:10.1039/c6ra20450c

Arregi, A., Amutio, M., Lopez, G., Bilbao, J., and Olazar, M. (2018). Evaluation of Thermochemical Routes for Hydrogen Production from Biomass: A Review. Amsterdam, Netherlands: Energy Conversion and Management, Energ. Convers. Manage. 165, 696-719. doi:10.1016/j.enconman.2018.03.089

Asadullah, M., Miyazawa, T., Ito, S. I., Kunimori, K., Koyama, S., and Tomishige, K. (2004). A Comparison of $\mathrm{Rh} / \mathrm{CeO} 2 / \mathrm{SiO} 2$ Catalysts with Steam Reforming Catalysts, Dolomite and Inert Materials as Bed Materials in Low Throughput Fluidized Bed Gasification Systems. Amsterdam, Netherlands: Biomass and Bioenergy. doi:10.1016/S0961-9534(03)00105-3

Ashok, J., Kumar, S. N., Subrahmanyam, M., and Venugopal, A. (2008). Pure H2 Production by Decomposition of Methane over $\mathrm{Ni}$ Supported on 
Hydroxyapatite Catalysts. Catal. Lett. 121, 283-290. doi:10.1007/s10562-0079334-z

Ashok, J., Kumar, S. N., Venugopal, A., Kumari, V. D., Tripathi, S., and Subrahmanyam, M. (2008). CO Free Hydrogen by Methane Decomposition over Activated Carbons. Catal. Commun. 9, 164-169. doi:10.1016/ j.catcom.2007.05.046

Ashok, J., Raju, G., Reddy, P. S., Subrahmanyam, M., and Venugopal, A. (2008). Catalytic Decomposition of $\mathrm{CH} 4$ over NiO-Al2O3-SiO2 Catalysts: Influence of Catalyst Preparation Conditions on the Production of H2. Int. J. Hydrogen Energ. 33, 4809-4818. doi:10.1016/j.ijhydene.2008.06.004

Avcıŏlu, A. O., Dayığlu, M. A., and Türker, U. (2019). Assessment of the Energy Potential of Agricultural Biomass Residues in Turkey. Renew. Energ. 138, 610-619. doi:10.1016/j.renene.2019.01.053

Avdeeva, L. B., Reshetenko, T. V., Ismagilov, Z. R., and Likholobov, V. A. (2002). Iron-containing Catalysts of Methane Decomposition: Accumulation of Filamentous Carbon. Appl. Catal. A. Gen. 228 (1-2), 53-63. doi:10.1016/ S0926-860X(01)00959-0

Awadallah, A. E., Aboul-Enein, A. A., and Aboul-Gheit, A. K. (2013). Various Nickel Doping in Commercial Ni-Mo/Al2O3 as Catalysts for Natural Gas Decomposition to COx-free Hydrogen Production. Renew. Energ. 57, 671-678. doi:10.1016/j.renene.2013.02.024

Awadallah, A. E., Mostafa, M. S., Aboul-Enein, A. A., and Hanafi, S. A. (2014). Hydrogen Production via Methane Decomposition over Al2O3-TiO2 Binary Oxides Supported Ni Catalysts: Effect of Ti Content on the Catalytic Efficiency. Fuel 129, 68-77. doi:10.1016/j.fuel.2014.03.047

Baharuddin, N. A., Wan Yusoff, W. N. A., Abd Aziz, A. J., and Mohd Tahir, N. N. (2021). Hydrogen Fuel Cells for Sustainable Energy: Development and Progress in Selected Developed Countries. IOP Conf. Ser. Mater. Sci. Eng. 1078, 012011. doi:10.1088/1757-899x/1078/1/012011

Baig, N., Kammakakam, I., and Falath, W. (2021). Nanomaterials: a Review of Synthesis Methods, Properties, Recent Progress, and Challenges. Mater. Adv. 2, 1821-1871. doi:10.1039/d0ma00807a

Baker, R. T. K., Barber, M. A., Harris, P. S., Feates, F. S., and Waite, R. J. (1972). Nucleation and Growth of Carbon Deposits from the Nickel Catalyzed Decomposition of Acetylene. J. Catal. 26 (1), 51-62. doi:10.1016/00219517(72)90032-2

Bockris, J. O. M. (2013). The Hydrogen Economy: Its History. Int. J. Hydrogen Energ. 38, 2579-2588. doi:10.1016/j.ijhydene.2012.12.026

Bonura, G., Di Blasi, O., Spadaro, L., Arena, F., and Frusteri, F. (2006). A Basic Assessment of the Reactivity of Ni Catalysts in the Decomposition of Methane for the Production of "COx-free" Hydrogen for Fuel Cells Application. Catal. Today 116, 298-303. doi:10.1016/j.cattod.2006.05.075

Brandon, N. P., and Kurban, Z. (2017). Clean Energy and the Hydrogen Economy. Phil. Trans. R. Soc. A. 375, 20160400. doi:10.1098/rsta.2016.0400

Budama, V. K., Johnson, N. G., Ermanoski, I., and Stechel, E. B. (2021). Technoeconomic Analysis of Thermochemical Water-Splitting System for Coproduction of Hydrogen and Electricity. Int. J. Hydrogen Energ. 46, 1656-1670. doi:10.1016/j.ijhydene.2020.10.060

Calzada Hernandez, A. R., Gibran González Castañeda, D., Sánchez Enriquez, A., de Lasa, H., and Serrano Rosales, B. (2020). Ru-Promoted Ni $/ \gamma$ Al2O3 Fluidized Catalyst for Biomass Gasification. Catalysts 10, 316. doi:10.3390/catal10030316

Cao, S., and Yu, J. (2016). Carbon-based H2-Production Photocatalytic Materials. J. Photochem. Photobiol. C: Photochem. Rev. 27, 72-99. doi:10.1016/ j.jphotochemrev.2016.04.002

Cao, Z., Zhu, X., Li, K., Wei, Y., He, F., and Wang, H. (2020). Moderatetemperature Chemical Looping Splitting of $\mathrm{CO} 2$ and $\mathrm{H} 2 \mathrm{O}$ for Syngas Generation. Chem. Eng. J. 397, 125393. doi:10.1016/j.cej.2020.125393

Carapellucci, R., and Giordano, L. (2020). Steam, Dry and Autothermal Methane Reforming for Hydrogen Production: A Thermodynamic Equilibrium Analysis. J. Power Sourc. 469, 228391. doi:10.1016/j.jpowsour.2020.228391

Carroquino, J., Bernal-Agustín, J.-L., and Dufo-López, R. (2019). Standalone Renewable Energy and Hydrogen in an Agricultural Context: A Demonstrative Case. Sustainability 11, 951. doi:10.3390/su11040951

Chai, R., Fan, S., Zhang, Z., Chen, P., Zhao, G., Liu, Y., et al. (2017). Free-Standing $\mathrm{NiO}-\mathrm{MgO}-\mathrm{Al} 2 \mathrm{O} 3$ Nanosheets Derived from Layered Double Hydroxides Grown onto FeCrAl-Fiber as Structured Catalysts for Dry Reforming of Methane. ACS Sustain. Chem. Eng. 5, 4517-4522. doi:10.1021/ acssuschemeng.7b00717
Chao, Y., Huang, C. T., Lee, H. M., and Chang, M. B. (2008). Hydrogen Production via Partial Oxidation of Methane with Plasma-Assisted Catalysis. Int. J. Hydrogen Energ. 33, 664-671. doi:10.1016/j.ijhydene.2007.09.024

Chen, A., Guo, H., Song, Y., Chen, P., and Lou, H. (2017). Recyclable CeO2-ZrO2 and $\mathrm{CeO} 2-\mathrm{TiO} 2$ Mixed Oxides Based Pt Catalyst for Aqueous-phase Reforming of the Low-Boiling Fraction of Bio-Oil. Int. J. Hydrogen Energ. 42, 9577-9588. doi:10.1016/j.ijhydene.2017.03.092

Chen, A., Liu, C., Liu, Y., and Zhang, L. (2019). Uranium Thermochemical Cycle Used for Hydrogen Production. Nucl. Eng. Tech. 51, 214-220. doi:10.1016/ j.net.2018.08.018

Chen, H., Yu, H., Tang, Y., Pan, M., Yang, G., Peng, F., et al. (2009). Hydrogen Production via Autothermal Reforming of Ethanol over noble Metal Catalysts Supported on Oxides. J. Nat. Gas Chem. 18 (2), 191-198. doi:10.1016/S10039953(08)60106-1

Chen, J., Song, W., and Xu, D. (2019). Compact Steam-Methane Reforming for the Production of Hydrogen in Continuous Flow Microreactor Systems. ACS Omega 4, 15600-15614. doi:10.1021/acsomega.9b02063

Chen, L.-N., Li, H.-Q., Yan, M.-W., Yuan, C.-F., Zhan, W.-W., Jiang, Y.-Q., et al. (2017). Ternary Alloys Encapsulated within Different MOFs via a SelfSacrificing Template Process: A Potential Platform for the Investigation of Size-Selective Catalytic Performances. Small 13, 1700683. doi:10.1002/ smll.201700683

Chen, L., Qi, Z., Zhang, S., Su, J., and Somorjai, G. A. (2020). Catalytic Hydrogen Production from Methane: A Review on Recent Progress and Prospect. Catalysts 10, 858. doi:10.3390/catal10080858

Chen, Y., Mu, X., Luo, X., Shi, K., Yang, G., and Wu, T. (2020). Catalytic Conversion of Methane at Low Temperatures: A Critical Review. Energy Technol. 8, 1900750. doi:10.1002/ente.201900750

Chesnokov, V. V., and Chichkan, A. S. (2009). Production of Hydrogen by Methane Catalytic Decomposition over $\mathrm{Ni}-\mathrm{Cu}-\mathrm{Fe} / \mathrm{Al} 2 \mathrm{O} 3$ Catalyst. Int. J. Hydrogen Energ. 34, 2979-2985. doi:10.1016/j.ijhydene.2009.01.074

Chew, T. L., and Bhatia, S. (2009). Effect of Catalyst Additives on the Production of Biofuels from palm Oil Cracking in a Transport Riser Reactor. Bioresour. Tech. 100, 2540-2545. doi:10.1016/j.biortech.2008.12.021

Cunha, A. F., Órfão, J. J. M., and Figueiredo, J. L. (2008). Catalytic Decomposition of Methane on Raney-type Catalysts. Appl. Catal. A: Gen. 348, 103-112. doi:10.1016/j.apcata.2008.06.028

Daneshmand-Jahromi, S., Rahimpour, M., Meshksar, M., and Hafizi, A. (2017). Hydrogen Production from Cyclic Chemical Looping Steam Methane Reforming over Yttrium Promoted Ni/SBA-16 Oxygen Carrier. Catalysts 7, 286. doi:10.3390/catal7100286

Dantas, S. C., Escritori, J. C., Soares, R. R., and Hori, C. E. (2010). Effect of Different Promoters on Ni/CeZrO2 Catalyst for Autothermal Reforming and Partial Oxidation of Methane. Chem. Eng. J. 156, 380-387. doi:10.1016/ j.cej.2009.10.047

Davda, R. R., Shabaker, J. W., Huber, G. W., Cortright, R. D., and Dumesic, J. A. (2005). A Review of Catalytic Issues and Process Conditions for Renewable Hydrogen and Alkanes by Aqueous-phase Reforming of Oxygenated Hydrocarbons over Supported Metal Catalysts. Appl. Catal. B: Environ. 56, 171-186. doi:10.1016/j.apcatb.2004.04.027

De Vlieger, D. J. M., Mojet, B. L., Lefferts, L., and Seshan, K. (2012). Aqueous Phase Reforming of Ethylene Glycol - Role of Intermediates in Catalyst Performance. J. Catal. 292, 239-245. doi:10.1016/j.jcat.2012.05.019

Di Michele, A., Dell'Angelo, A., Tripodi, A., Bahadori, E., Sànchez, F., Motta, D., et al. (2019). Steam Reforming of Ethanol over Ni/MgAl2O4 Catalysts. Int. J. Hydrogen Energ. 44, 952-964. doi:10.1016/j.ijhydene.2018.11.048

Digraskar, R. V., Sapner, V. S., Mali, S. M., Narwade, S. S., Ghule, A. V., and Sathe, B. R. (2019). CZTS Decorated on Graphene Oxide as an Efficient Electrocatalyst for High-Performance Hydrogen Evolution Reaction. ACS Omega 4, 7650-7657. doi:10.1021/acsomega.8b03587

Dufour, J., Gálvez, J. L., Serrano, D. P., Moreno, J., and Martínez, G. (2010). Life Cycle Assessment of Hydrogen Production by Methane Decomposition Using Carbonaceous Catalysts. Int. J. Hydrogen Energ. 35, 1205-1212. doi:10.1016/ j.ijhydene.2009.11.093

Dufour, J., Serrano, D., Gálvez, J., Moreno, J., and García, C. (2009). Life Cycle Assessment of Processes for Hydrogen Production. Environmental Feasibility and Reduction of Greenhouse Gases Emissions. Int. J. Hydrogen Energ. 34, 1370-1376. doi:10.1016/j.ijhydene.2008.11.053 
Dufour, J., Serrano, D. P., Gálvez, J. L., González, A., Soria, E., and Fierro, J. L. G. (2012). Life Cycle Assessment of Alternatives for Hydrogen Production from Renewable and Fossil Sources. Int. J. Hydrogen Energ. 37, 1173-1183. doi:10.1016/j.ijhydene.2011.09.135

El Hakim, S., Chave, T., Nada, A. A., Roualdes, S., and Nikitenko, S. I. (2021). Tailoring Noble Metal-free Ti@TiO2 Photocatalyst for Boosting Photothermal Hydrogen Production. Front. Catal. 1. doi:10.3389/ fctls.2021.669260

El-Shafie, M., Kambara, S., and Hayakawa, Y. (2019). Hydrogen Production Technologies Overview. Jpee 07, 107-154. doi:10.4236/jpee.2019.71007

Eljack, F., and Kazi, M.-K. (2021). Prospects and Challenges of Green Hydrogen Economy via Multi-Sector Global Symbiosis in Qatar. Front. Sustain. 1. doi:10.3389/frsus.2020.612762

Ertl, G., Knözinger, H., and Weitkamp, J. (2008). Handbook of Heterogeneous Catalysis. Handbook Heterogeneous Catal.. doi:10.1524/ zpch.1999.208.part_1_2.27410.1002/9783527619474

Fakeeha, A., Ibrahim, A. A., Aljuraywi, H., Alqahtani, Y., Alkhodair, A., Alswaidan, S., et al. (2020). Hydrogen Production by Partial Oxidation Reforming of Methane over Ni Catalysts Supported on High and Low Surface Area Alumina and Zirconia. Processes 8, 499. doi:10.3390/PR8050499

Farsi, A., and Mansouri, S. S. (2016). Influence of Nanocatalyst on Oxidative Coupling, Steam and Dry Reforming of Methane: A Short Review. Arabian J. Chem. 9, S28-S34. doi:10.1016/j.arabjc.2011.08.001

Fasolini, A., Cucciniello, R., Paone, E., Mauriello, F., and Tabanelli, T. (2019). A Short Overview on the Hydrogen Production via Aqueous Phase Reforming (APR) of Cellulose, C6-C5 Sugars and Polyols. Catalysts 9, 917. doi:10.3390/ catal9110917

Figen, H. E., and Baykara, S. Z. (2018). Effect of Ruthenium Addition on Molybdenum Catalysts for Syngas Production via Catalytic Partial Oxidation of Methane in a Monolithic Reactor. Int. J. Hydrogen Energ. 43, 1129-1138. doi:10.1016/j.ijhydene.2017.10.173

Francke, R., Schille, B., and Roemelt, M. (2018). Homogeneously Catalyzed Electroreduction of Carbon Dioxide-Methods, Mechanisms, and Catalysts. Chem. Rev. 118, 4631-4701. doi:10.1021/acs.chemrev.7b00459

Frontera, P., Macario, A., Ferraro, M., and Antonucci, P. (2017). Supported Catalysts for CO2 Methanation: A Review. Catalysts 7, 59. doi:10.3390/ catal7020059

Gao, B., Wang, I.-W., Ren, L., Haines, T., and Hu, J. (2019). Catalytic Performance and Reproducibility of $\mathrm{Ni} / \mathrm{Al} 2 \mathrm{O} 3$ and $\mathrm{Co} / \mathrm{Al} 2 \mathrm{O} 3$ Mesoporous Aerogel Catalysts for Methane Decomposition. Ind. Eng. Chem. Res. 58, 798-807. Industrial and Engineering Chemistry Research. 2020. doi:10.1021/acs.iecr.8b0422310.1021/ acs.iecr.9b06957

Ghavam, S., Vahdati, M., Wilson, I. A. G., and Styring, P. (2021). Sustainable Ammonia Production Processes. Front. Energ. Res. 9. doi:10.3389/ fenrg.2021.580808

Ghoneim, S. A., El-Salamony, R. A., and El-Temtamy, S. A. (2016). Review on Innovative Catalytic Reforming of Natural Gas to Syngas. Wjet 04, 116-139. doi:10.4236/wjet.2016.41011

Gmehling, J., Kleiber, M., Kolbe, B., and Rarey, J. (2019). Chemical Thermodynamics for Process Simulation. Hoboken, NJ: Chemical Thermodynamics for Process Simulation. doi:10.1002/9783527809479

Gokon, N., Sagawa, S., and Kodama, T. (2013). Comparative Study of Activity of Cerium Oxide at thermal Reduction Temperatures of $1300-1550{ }^{\circ} \mathrm{C}$ for Solar Thermochemical Two-step Water-Splitting Cycle. Int. J. Hydrogen Energ. 38, 14402-14414. doi:10.1016/j.ijhydene.2013.08.108

Grigoriev, S., Porembsky, V., and Fateev, V. (2006). Pure Hydrogen Production by PEM Electrolysis for Hydrogen Energy. Int. J. Hydrogen Energ. 31, 171-175. doi:10.1016/j.ijhydene.2005.04.038

Gumina, B., Espro, C., Galvagno, S., Pietropaolo, R., and Mauriello, F. (2019). Bioethanol Production from Unpretreated Cellulose under Neutral Selfsustainable Hydrolysis/Hydrogenolysis Conditions Promoted by the Heterogeneous Pd/Fe3O4 Catalyst. ACS Omega 4, 352-357. doi:10.1021/ acsomega.8b03088

Gupta, M., Smith, M. L., and Spivey, J. J. (2011). Heterogeneous Catalytic Conversion of Dry Syngas to Ethanol and Higher Alcohols on Cu-Based Catalysts. ACS Catal. 1, 641-656. doi:10.1021/cs2001048

Ha, Q. L. M., Lund, H., Kreyenschulte, C., Bartling, S., Atia, H., Vuong, T. H., et al. (2020). Development of Highly Stable Low Ni Content Catalyst for Dry
Reforming of $\mathrm{CH} 4$-Rich Feedstocks. ChemCatChem 12, 1562-1568. doi:10.1002/cctc.201902066

Hakouk, K., Klotz, M., Di Geronimo, E., Ranieri, V., Pieterse, J. A. Z., Aranda Almansa, G., et al. (2018). Implementation of Novel Ice-Templated Materials for Conversion of Tars from Gasification Product Gas. Fuel Process. Tech. 181, 340-351. doi:10.1016/j.fuproc.2018.10.009

Hallenbeck, P. C., Lazaro, C. Z., and Sagır, E. (2019). Comprehensive Biotechnology. Biohydrogen, 128-139. doi:10.1016/B978-0-444-640468.00155-5

Harun, K., Adhikari, S., and Jahromi, H. (2020). Hydrogen Production via Thermocatalytic Decomposition of Methane Using Carbon-Based Catalysts. RSC Adv. 10, 40882-40893. doi:10.1039/D0RA07440C

Hasnan, N. S. N., Timmiati, S. N., Lim, K. L., Yaakob, Z., Kamaruddin, N. H. N., and Teh, L. P. (2020). Recent Developments in Methane Decomposition over Heterogeneous Catalysts: an Overview. Mater. Renew. Sustain. Energ. 9. doi:10.1007/s40243-020-00167-5

Hasnan, N. S. N., Timmiati, S. N., Pudukudy, M., Yaakob, Z., Lim, K. L., and Taufiq-Yap, Y. H. (2020). Catalytic Decomposition of Methane into Hydrogen and Carbon Nanotubes over Mesostructured Silica Nanoparticle-Supported Nickel Catalysts. J. Porous Mater. 27, 369-382. doi:10.1007/s10934-01900819-6

Haynes, D. J., and Shekhawat, D. (2011). Fuel Cells: Technologies for Fuel Processing. Oxidative Steam Reforming, 129-190. doi:10.1016/B978-0-44453563-4.10006-9

He, L., Yang, J., and Chen, D. (2013). “Hydrogen from Biomass,". Editors LM Gandía, G Arzamendi, and PMBT. RHT Diéguez (Amsterdam: Elsevier), 111-133. doi:10.1016/B978-0-444-56352-1.00006-4

Heidenreich, S., Müller, M., and Foscolo, P. U. (2016). Advanced Biomass Gasification: New Concepts for Efficiency Increase and Product Flexibility. doi:10.1016/C2015-0-01777-4

Hongloi, N., Prapainainar, P., Seubsai, A., Sudsakorn, K., and Prapainainar, C. (2019). Nickel Catalyst with Different Supports for green Diesel Production. Energy 182, 306-320. doi:10.1016/j.energy.2019.06.020

Horn, R., and Schlögl, R. (2015). Methane Activation by Heterogeneous Catalysis. Catal. Lett. 145, 23-39. doi:10.1007/s10562-014-1417-z

Hosseini, S. M. S., Hashemipour rafsanjani, H., and Talebizadeh, A. R. (2017). Methane Oxy-Steam Reforming over a Highly Efficient Ni/Al2O3 Nanocatalyst Prepared by Microwave-Assisted Impregnation Method. Iran J. Chem. Eng. 14, 3-16. Available: http://www.ijche.com/article_58588.html.

Hs, R., Kw, J., Ws, D., Sc, B., and Se, P. (2002). Methane Reforming Reactions over Stable Ni/ $\theta-\mathrm{Al} 2 \mathrm{O} 3$ Catalysts. J. Ind. Eng. Chem. 8, 464-471. Available: https:// www.cheric.org/research/tech/periodicals/view.php?seq=384337.

Huber, G. W., Shabaker, J. W., Evans, S. T., and Dumesic, J. A. (2006). Aqueousphase Reforming of Ethylene Glycol over Supported Pt and Pd Bimetallic Catalysts. Appl. Catal. B: Environ. 62, 226-235. doi:10.1016/ j.apcatb.2005.07.010

Hydrogen Council (2017). Hydrogen Scaling up: A Sustainable Pathway for the Global Energy Transition. Brussels, Belgium: Hydrog scaling up A Sustain Pathw Glob energy Transit.

Ibrahim, A. A., Al-Fatesh, A. S., Khan, W. U., Soliman, M. A., Al Otaibi, R. L., and Fakeeha, A. H. (2015). Thermo-catalytic Methane Decomposition: A Review of State of the Art of Catalysts. J. Chem. Soc. Pakistan 2 (1), 35-40. doi:10.5185/ amp. 2017/109

Inaba, M., Zhang, Z., Matsuoka, K., and Soneda, Y. (2019). Optimization of the Reaction Conditions for Fe-Catalyzed Decomposition of Methane and Characterization of the Produced Nanocarbon Fibers. Catal. Today 332, 11-19. doi:10.1016/j.cattod.2018.11.014

Jackson, S. D. (1995). Catalysis: an Integrated Approach to Homogeneous, Heterogeneous, and Industrial Catalysis. Chem. Eng. J. Biochem. Eng. J., 159-197. doi:10.1016/0923-0467(95)80011-5

Jana, P., de la Peña O'Shea, V. A., Coronado, J. M., and Serrano, D. P. (2010). Cobalt Based Catalysts Prepared by Pechini Method for CO2-free Hydrogen Production by Methane Decomposition. Int. J. Hydrogen Energ. 35, 10285-10294. doi:10.1016/j.ijhydene.2010.07.125

Jeong, H., Kim, K. I., Kim, T. H., Ko, C. H., Park, H. C., and Song, I. K. (2006). Hydrogen Production by Steam Reforming of Methanol in a Micro-channel Reactor Coated with $\mathrm{Cu} / \mathrm{ZnO} / \mathrm{ZrO} 2 / \mathrm{Al} 2 \mathrm{O} 3$ Catalyst. J. Power Sourc. 159, 1296-1299. doi:10.1016/j.jpowsour.2005.11.095 
Jeong, K.-E., Kim, H.-D., Kim, T.-W., Kim, J.-W., Chae, H.-J., Jeong, S.-Y., et al. (2014). Hydrogen Production by Aqueous Phase Reforming of Polyols over Nano- and Micro-sized Mesoporous Carbon Supported Platinum Catalysts. Catal. Today 232, 151-157. doi:10.1016/j.cattod.2014.02.005

Kannaiyan, S., Madhavan, V. R., Rajagopal, S., and Jayabalan, A. (2016). An Experimental Analysis on Tar Cracking Using Nano Structured Ni-Co/Si-P Catalyst in a Biomass Gasifier-Based Power Generating System. Appl. Therm. Eng. 97, 13-21. doi:10.1016/j.applthermaleng.2015.10.150

Karaca, A. E., and Dincer, I. (2020). Hydrogen Energy Related Research and Development Efforts in Canada: A Perspective. Int. J. Energ. Res 44, 9246-9253. doi:10.1002/er.5895

Karaismailoglu, M., Figen, H. E., and Baykara, S. Z. (2019). Hydrogen Production by Catalytic Methane Decomposition over Yttria Doped Nickel Based Catalysts. Int. J. Hydrogen Energ. 44, 9922-9929. doi:10.1016/j.ijhydene.2018.12.214

Katheria, S., Gupta, A., Deo, G., and Kunzru, D. (2016). Effect of Calcination Temperature on Stability and Activity of $\mathrm{Ni} / \mathrm{MgAl} 2 \mathrm{O} 4$ Catalyst for Steam Reforming of Methane at High Pressure Condition. Int. J. Hydrogen Energ. 41, 14123-14132. doi:10.1016/j.ijhydene.2016.05.109

Kayfeci, M., Keçebaş, A., and Bayat, M. (2019). Hydrogen Production. Solar Hydrogen Production: Processes. Syst. Tech., 45-83. doi:10.1016/B978-0-12814853-2.00003-5

Keipi, T., Hankalin, V., Nummelin, J., and Raiko, R. (2016). Techno-economic Analysis of Four Concepts for thermal Decomposition of Methane: Reduction of CO 2 Emissions in Natural Gas Combustion. Energ. Convers. Manage. 110, 1-12. doi:10.1016/j.enconman.2015.11.057

Khan, W. U., Fakeeha, A. H., Al-Fatesh, A. S., Ibrahim, A. A., and Abasaeed, A. E. (2016). La 2 O 3 Supported Bimetallic Catalysts for the Production of Hydrogen and Carbon Nanomaterials from Methane. Int. J. Hydrogen Energ. 41, 976-983. doi:10.1016/j.ijhydene.2015.10.112

Khani, Y., Shariatinia, Z., and Bahadoran, F. (2016). High Catalytic Activity and Stability of ZnLaAlO 4 Supported Ni, Pt and Ru Nanocatalysts Applied in the Dry, Steam and Combined Dry-Steam Reforming of Methane. Chem. Eng. J. 299, 353-366. doi:10.1016/j.cej.2016.04.108

Kim, C.-H., Han, J.-Y., Kim, S., Lee, B., Lim, H., Lee, K.-Y., et al. (2018). Hydrogen Production by Steam Methane Reforming in a Membrane Reactor Equipped with a Pd Composite Membrane Deposited on a Porous Stainless Steel. Int. J. Hydrogen Energ. 43, 7684-7692. doi:10.1016/j.ijhydene.2017.11.176

Kim, D., Kwak, B. S., Min, B.-K., and Kang, M. (2015). Characterization of Ni and W Co-loaded SBA-15 Catalyst and its Hydrogen Production Catalytic Ability on Ethanol Steam Reforming Reaction. Appl. Surf. Sci. 332, 736-746. doi:10.1016/j.apsusc.2014.12.180

Kim, H.-D., Kim, T.-W., Park, H. J., Jeong, K.-E., Chae, H.-J., Jeong, S.-Y., et al. (2012). Hydrogen Production via the Aqueous Phase Reforming of Ethylene Glycol over Platinum-Supported Ordered Mesoporous Carbon Catalysts: Effect of Structure and Framework-Configuration. Int. J. Hydrogen Energ. 37, 12187-12197. doi:10.1016/j.ijhydene.2012.05.126

Kim, H.-D., Park, H. J., Kim, T.-W., Jeong, K.-E., Chae, H.-J., Jeong, S.-Y., et al. (2012). The Effect of Support and Reaction Conditions on Aqueous Phase Reforming of Polyol over Supported Pt-Re Bimetallic Catalysts. Catal. Today 185, 73-80. doi:10.1016/j.cattod.2011.08.012

Kim, J.-E., Kim, E.-J., Chen, H., Wu, C.-H., Adams, M. W. W., and Zhang, Y.-H. P. (2017). Advanced Water Splitting for green Hydrogen Gas Production through Complete Oxidation of Starch by In Vitro Metabolic Engineering. Metab. Eng. 44, 246-252. doi:10.1016/j.ymben.2017.09.015

Kim, J., Kim, H.-R., and Choung, S.-J. (2011). The Characterization and Hydrogen Production from Water Decomposition with Methanol in a Semi-batch Type Reactor Using in, P-TiO2s. Int. J. Photoenergy 2011, 1-7. doi:10.1155/2011/359161

Koepf, E., Villasmil, W., and Meier, A. (2016). Pilot-scale Solar Reactor Operation and Characterization for Fuel Production via the $\mathrm{Zn} / \mathrm{ZnO}$ Thermochemical Cycle. Appl. Energ. 165, 1004-1023. doi:10.1016/j.apenergy.2015.12.106

Koh, A., Chen, L., Keeleong, W., Johnson, B., Khimyak, T., and Lin, J. (2007). Hydrogen or Synthesis Gas Production via the Partial Oxidation of Methane over Supported Nickel-Cobalt Catalysts. Int. J. Hydrogen Energ. 32, 725-730. doi:10.1016/j.ijhydene.2006.08.002

Konsolakis, M., Ioakimidis, Z., Kraia, T., and Marnellos, G. (2016). Hydrogen Production by Ethanol Steam Reforming (ESR) over CeO2 Supported Transition Metal ( $\mathrm{Fe}, \mathrm{Co}, \mathrm{Ni}, \mathrm{Cu}$ ) Catalysts: Insight into the StructureActivity Relationship. Catalysts 6, 39. doi:10.3390/catal6030039
Kosinov, N., Uslamin, E. A., Meng, L., Parastaev, A., Liu, Y., and Hensen, E. J. M. (2019). Reversible Nature of Coke Formation on Mo/ZSM-5 Methane Dehydroaromatization Catalysts. Angew. Chem. Int. Ed. 58, 7068-7072. doi:10.1002/anie.201902730

Kramer, M., McKelvie, M., and Watson, M. (2018). Additive Manufacturing of Catalyst Substrates for Steam-Methane Reforming. J. Materi Eng. Perform. 27, 21-31. doi:10.1007/s11665-017-2859-4

Kumar, G., Shobana, S., Chen, W.-H., Bach, Q.-V., Kim, S. H., Atabani, A. E., et al. (2017). A Review of Thermochemical Conversion of Microalgal Biomass for Biofuels: Chemistry and Processes. Green. Chem. 19, 44-67. doi:10.1039/ c6gc01937d

Kumar, R., Kumar, K., Choudary, N. V., and Pant, K. K. (2019). Effect of Support Materials on the Performance of Ni-Based Catalysts in Tri-reforming of Methane. Fuel Process. Tech. 186, 40-52. doi:10.1016/j.fuproc.2018.12.018

Landman, A., Dotan, H., Shter, G. E., Wullenkord, M., Houaijia, A., Maljusch, A., et al. (2017). Photoelectrochemical Water Splitting in Separate Oxygen and Hydrogen Cells. Nat. Mater 16, 646-651. doi:10.1038/nmat4876

Lázaro, M. J., Echegoyen, Y., Suelves, I., Palacios, J. M., and Moliner, R. (2007). Decomposition of Methane over Ni-SiO2 and Ni-Cu-SiO2 Catalysts: Effect of Catalyst Preparation Method. Appl. Catal. A: Gen. 329, 22-29. doi:10.1016/ j.apcata.2007.06.014

Leal Pérez, B. J., Medrano Jiménez, J. A., Bhardwaj, R., Goetheer, E., van Sint Annaland, M., and Gallucci, F. (2021). Methane Pyrolysis in a Molten Gallium Bubble Column Reactor for Sustainable Hydrogen Production: Proof of Concept \& Techno-Economic Assessment. Int. J. Hydrogen Energ. 46, 4917-4935. doi:10.1016/j.ijhydene.2020.11.079

Li, B., Su, W., Lin, X., and Wang, X. (2017). Catalytic Performance and Characterization of Neodymium-Containing Mesoporous Silica Supported Nickel Catalysts for Methane Reforming to Syngas. Int. J. Hydrogen Energ. 42, 12197-12209. doi:10.1016/j.ijhydene.2017.03.159

Li, J., Lu, G., Li, K., and Wang, W. (2004). Active Nb2O5-Supported Nickel and Nickel-Copper Catalysts for Methane Decomposition to Hydrogen and Filamentous Carbon. J. Mol. Catal. A: Chem. 221, 105-112. doi:10.1016/ j.molcata.2004.06.015

Li, M., Duanmu, K., Wan, C., Cheng, T., Zhang, L., Dai, S., et al. (2019). Singleatom Tailoring of Platinum Nanocatalysts for High-Performance Multifunctional Electrocatalysis. Nat. Catal. 2, 495-503. doi:10.1038/s41929019-0279-6

Li, Y., Chen, J., Qin, Y., and Chang, L. (2000). Simultaneous Production of Hydrogen and Nanocarbon from Decomposition of Methane on a NickelBased Catalyst. Energy Fuels 14, 1188-1194. doi:10.1021/ef0000781

Li, Y., Guo, L., Zhang, X., Jin, H., and Lu, Y. (2010). Hydrogen Production from Coal Gasification in Supercritical Water with a Continuous Flowing System. Int. J. Hydrogen Energ. 35, 3036-3045. doi:10.1016/ j.ijhydene.2009.07.023

Lian, C., Yu, Y., Zhang, K., Gao, A., and Wang, Y. (2018). Highly Efficient FischerTropsch Synthesis over an Alumina-Supported Ruthenium Catalyst. Catal. Sci. Technol. 8, 1528-1534. doi:10.1039/c7cy02361h

Lua, A. C., and Wang, H. Y. (2013). Decomposition of Methane over Unsupported Porous Nickel and alloy Catalyst. Appl. Catal. B: Environ. 132-133, 469-478. doi:10.1016/j.apcatb.2012.12.014

Ma, Y., Ma, Y., Zhao, Z., Hu, X., Ye, Z., Yao, J., et al. (2019). Comparison of Fibrous Catalysts and Monolithic Catalysts for Catalytic Methane Partial Oxidation. Renew. Energ. 138, 1010-1017. doi:10.1016/j.renene.2019.02.027

Ma, Z., Yuan, H., Sun, J., Yang, J., Tang, B., Wang, X., et al. (2021). Versatile Construction of a Hierarchical Porous Electrode and its Application in Electrochemical Hydrogen Production: a Mini Review. Mater. Adv. 2, 1177-1189. doi:10.1039/d0ma00825g

Mei Wu, L., Hui Zhou, C., Shen Tong, D., and Hua Yu, W. (2014). Catalytic Thermochemical Processes for Biomass Conversion to Biofuels and Chemicals. Bioenergy Res. Adv. Appl., 243-254. doi:10.1016/B978-0-44459561-4.00015-2

Meryemoglu, B., Hesenov, A., Irmak, S., Atanur, O. M., and Erbatur, O. (2010). Aqueous-phase Reforming of Biomass Using Various Types of Supported Precious Metal and Raney-Nickel Catalysts for Hydrogen Production. Int. J. Hydrogen Energ. 35, 12580-12587. doi:10.1016/j.ijhydene.2010.08.046

Moliner, R., Echegoyen, Y., Suelves, I., Lázaro, M., and Palacios, J. (2008). Ni-Mg and Ni-Cu-Mg Catalysts for Simultaneous Production of Hydrogen and 
Carbon nanofibers The Effect of Calcination Temperature. Int. J. Hydrogen Energ. 33, 1719-1728. doi:10.1016/j.ijhydene.2008.01.005

Molino, A., Chianese, S., and Musmarra, D. (2016). Biomass Gasification Technology: The State of the Art Overview. J. Energ. Chem. 25, 10-25. doi:10.1016/j.jechem.2015.11.005

Molino, A., Larocca, V., Chianese, S., and Musmarra, D. (2018). Biofuels Production by Biomass Gasification: A Review. Energies 11, 811. doi:10.3390/en11040811

Mosinska, M., Szynkowska, M. I., and Mierczynski, P. (2020). Oxy-Steam Reforming of Natural Gas on Ni Catalysts-A Minireview. Catalysts 10, 896. doi:10.3390/catal10080896

Movasati, A., Alavi, S. M., and Mazloom, G. (2017). CO2 Reforming of Methane over Ni/ZnAl2O4 Catalysts: Influence of Ce Addition on Activity and Stability. Int. J. Hydrogen Energ. 42, 16436-16448. doi:10.1016/ j.ijhydene.2017.05.199

Musamali, R., and Isa, Y. M. (2018). A Novel Catalyst System for Methane Decomposition. Int. J. Energ. Res 42, 4372-4382. doi:10.1002/er.4175

Nikolaidis, P., and Poullikkas, A. (2017). A Comparative Overview of Hydrogen Production Processes. Renew. Sustain. Energ. Rev. 67, 597-611. doi:10.1016/ j.rser.2016.09.044

Niu, J., Wang, Y., Qi, Y., Dam, A. H., Wang, H., Zhu, Y.-A., et al. (2020). New Mechanism Insights into Methane Steam Reforming on Pt/Ni from DFT and Experimental Kinetic Study. Fuel 266, 117143. doi:10.1016/ j.fuel.2020.117143

Nuernberg, G. B., Fajardo, H. V., Mezalira, D. Z., Casarin, T. J., Probst, L. F. D., and Carreño, N. L. V. (2008). Preparation and Evaluation of Co/Al2O3 Catalysts in the Production of Hydrogen from Thermo-Catalytic Decomposition of Methane: Influence of Operating Conditions on Catalyst Performance. Fuel 87, 1698-1704. doi:10.1016/j.fuel.2007.08.005

Okolie, J. A., Rana, R., Nanda, S., Dalai, A. K., and Kozinski, J. A. (2019). Supercritical Water Gasification of Biomass: A State-Of-The-Art Review of Process Parameters, Reaction Mechanisms and Catalysis. Sustain. Energ. Fuels 3, 578-598. doi:10.1039/c8se00565f

Ouyang, M., Boldrin, P., Maher, R. C., Chen, X., Liu, X., Cohen, L. F., et al. (2019). A Mechanistic Study of the Interactions between Methane and Nickel Supported on Doped Ceria. Appl. Catal. B: Environ. 248, 332-340. doi:10.1016/j.apcatb.2019.02.038

Pantaleo, G., Parola, V. L., Deganello, F., Singha, R. K., Bal, R., and Venezia, A. M. (2016). Ni/CeO2 Catalysts for Methane Partial Oxidation: Synthesis Driven Structural and Catalytic Effects. Appl. Catal. B: Environ. 189, 233-241. doi:10.1016/j.apcatb.2016.02.064

Parkinson, B., Tabatabaei, M., Upham, D. C., Ballinger, B., Greig, C., Smart, S., et al. (2018). Hydrogen Production Using Methane: Techno-Economics of Decarbonizing Fuels and Chemicals. Int. J. Hydrogen Energ. 43, 2540-2555. doi:10.1016/j.ijhydene.2017.12.081

Patil, C. S., van Sint Annaland, M., and Kuipers, J. A. M. (2007). Fluidised Bed Membrane Reactor for Ultrapure Hydrogen Production via Methane Steam Reforming: Experimental Demonstration and Model Validation. Chem. Eng. Sci. 62, 2989-3007. doi:10.1016/j.ces.2007.02.022

Peng, W. X., Wang, L. S., Mirzaee, M., Ahmadi, H., Esfahani, M. J., and Fremaux, S. (2017). Hydrogen and Syngas Production by Catalytic Biomass Gasification. Energ. Convers. Manage. 135, 270-273. doi:10.1016/j.enconman.2016.12.056

Pinilla, J. L., Utrilla, R., Karn, R. K., Suelves, I., Lázaro, M. J., Moliner, R., et al. (2011). High Temperature Iron-Based Catalysts for Hydrogen and Nanostructured Carbon Production by Methane Decomposition. Int. J. Hydrogen Energ. 36, 7832-7843. doi:10.1016/j.ijhydene.2011.01.184

Pinton, N., Vidal, M. V., Signoretto, M., Martínez-Arias, A., and Cortés Corberán, V. (2017). Ethanol Steam Reforming on Nanostructured Catalysts of Ni, Co and $\mathrm{CeO} 2$ : Influence of Synthesis Method on Activity, Deactivation and Regenerability. Catal. Today 296, 135-143. doi:10.1016/j.cattod.2017.06.022

Pudukudy, M., Yaakob, Z., Jia, Q., and Sobri Takriff, M. (2018). Catalytic Decomposition of Undiluted Methane into Hydrogen and Carbon Nanotubes over Pt Promoted $\mathrm{Ni} / \mathrm{CeO} 2$ Catalysts. New J. Chem. 42, 14843-14856. doi:10.1039/C8NJ02842G

Qian, J. X., Chen, T. W., Enakonda, L. R., Liu, D. B., Basset, J.-M., and Zhou, L. (2020). Methane Decomposition to Pure Hydrogen and Carbon Nano Materials: State-Of-The-Art and Future Perspectives. Int. J. Hydrogen Energ. 45, 15721-15743. doi:10.1016/j.ijhydene.2020.04.100
Qu, H., He, S., Su, Y., Zhang, Y., and Su, H. (2020). MoSe2: a Promising Non-noble Metal Catalyst for Direct Ethanol Synthesis from Syngas. Fuel 281, 118760. doi:10.1016/j.fuel.2020.118760

Rogers, J. L., Mangarella, M. C., D’Amico, A. D., Gallagher, J. R., Dutzer, M. R., Stavitski, E., et al. (2016). Differences in the Nature of Active Sites for Methane Dry Reforming and Methane Steam Reforming over Nickel Aluminate Catalysts. ACS Catal. 6, 5873-5886. doi:10.1021/acscatal.6b01133

Roh, H. S., Jun, K. W., Dong, W. S., Park, S. E., and Baek, Y. S. (2001). Highly Stable $\mathrm{Ni}$ Catalyst Supported on Ce-ZrO2 for Oxy-Steam Reforming of Methane. Catal. Lett. 44 (5), 295. doi:10.1023/A:1016699317421

Rostrup-Nielsen, J. R. (1972). Equilibria of Decomposition Reactions of Carbon Monoxide and Methane over Nickel Catalysts. J. Catal. 27 (3), 343-356. doi:10.1016/0021-9517(72)90170-4

Rozzi, E., Minuto, F. D., Lanzini, A., and Leone, P. (2020). Green Synthetic Fuels: Renewable Routes for the Conversion of Non-fossil Feedstocks into Gaseous Fuels and Their End Uses. Energies 13, 420. doi:10.3390/en13020420

Saad, J. M., and Williams, P. T. (2016). Catalytic Dry Reforming of Waste Plastics from Different Waste Treatment Plants for Production of Synthesis Gases. Waste Manage. 58, 214-220. doi:10.1016/j.wasman.2016.09.011

Safari, F., and Dincer, I. (2020). A Review and Comparative Evaluation of Thermochemical Water Splitting Cycles for Hydrogen Production. Amsterdam, Netherlands: Energy Conversion and Management. Energ. Convers. Manage. 205, 112182. doi:10.1016/j.enconman.2019.112182

Saikia, P., Gogoi, C., Kalita, P. J., and Goswamee, R. L. (2020). Catalytic Conversion of High-GWP Gases N2O and CH4 to Syngas (H2 + CO) on SiO2@Ni-Cr Layered Nano-Oxide-Coated Monolithic Catalyst. Environ. Sci. Pollut. Res. 27, 24939-24953. doi:10.1007/s11356-020-08589-4

Salam, M. A., Ahmed, K., Akter, N., Hossain, T., and Abdullah, B. (2018). A Review of Hydrogen Production via Biomass Gasification and its prospect in Bangladesh. Int. J. Hydrogen Energ. 43, 14944-14973. doi:10.1016/ j.ijhydene.2018.06.043

Sánchez-Bastardo, N., Schlögl, R., and Ruland, H. (2020). Methane Pyrolysis for $\mathrm{CO} 2$-Free H 2 Production: A Green Process to Overcome Renewable Energies Unsteadiness. Chem. Ingenieur Technik 92, 1596-1609. doi:10.1002/ cite. 202000029

Saraswat, S. K., and Pant, K. K. (2013). Synthesis of Hydrogen and Carbon Nanotubes over Copper Promoted $\mathrm{Ni} / \mathrm{SiO} 2$ Catalyst by Thermocatalytic Decomposition of Methane. J. Nat. Gas Sci. Eng. 13, 52-59. doi:10.1016/ j.jngse.2013.04.001

Scapinello, M., Delikonstantis, E., and Stefanidis, G. D. (2017). The Panorama of Plasma-Assisted Non-oxidative Methane Reforming. Chem. Eng. Process. Process Intensification 117, 120-140. doi:10.1016/j.cep.2017.03.024

Serrano, D. P., Botas, J. Á., Pizarro, P., and Gómez, G. (2013). Kinetic and Autocatalytic Effects during the Hydrogen Production by Methane Decomposition over Carbonaceous Catalysts. Int. J. Hydrogen Energ. 38, 5671-5683. doi:10.1016/j.ijhydene.2013.02.112

Shang, Z., Li, S., Li, L., Liu, G., and Liang, X. (2017). Highly Active and Stable Alumina Supported Nickel Nanoparticle Catalysts for Dry Reforming of Methane. Appl. Catal. B: Environ. 201, 302-309. doi:10.1016/ j.apcatb.2016.08.019

Shen, Y., and Lua, A. C. (2015). Polyol Synthesis of Nickel-Copper Based Catalysts for Hydrogen Production by Methane Decomposition. Int. J. Hydrogen Energ. 40, 311-321. doi:10.1016/j.ijhydene.2014.10.071

Shen, Y., and Lua, A. C. (2015). Sol-gel Synthesis of Titanium Oxide Supported Nickel Catalysts for Hydrogen and Carbon Production by Methane Decomposition. J. Power Sourc. 280, 467-475. doi:10.1016/ j.jpowsour.2015.01.057

Shiva Kumar, S., and Himabindu, V. (2019). Hydrogen Production by PEM Water Electrolysis - A Review. Mater. Sci. Energ. Tech. 2, 442-454. doi:10.1016/ j.mset.2019.03.002

Siew, K. W., Lee, H. C., Gimbun, J., and Cheng, C. K. (2014). Characterization of La-Promoted Ni/Al2O3 Catalysts for Hydrogen Production from Glycerol Dry Reforming. J. Energ. Chem 23 (1), 15-21. doi:10.1016/S2095-4956(14)60112-1

Silva, F. A., Resende, K. A., Da Silva, A. M., De Souza, K. R., Mattos, L. V., Montes, M., et al. (2012). Syngas Production by Partial Oxidation of Methane over Pt/ CeZrO2/Al2O3 Catalysts. Catal. Today 180, 111-116. doi:10.1016/ j.cattod.2011.07.035 
Singha, R. K., Shukla, A., Yadav, A., Sivakumar Konathala, L. N., and Bal, R. (2017). Effect of Metal-Support Interaction on Activity and Stability of Ni-CeO2 Catalyst for Partial Oxidation of Methane. Appl. Catal. B: Environ. 202, 473-488. doi:10.1016/j.apcatb.2016.09.060

Singla, M. K., Nijhawan, P., and Oberoi, A. S. (2021). Hydrogen Fuel and Fuel Cell Technology for Cleaner Future: a Review. Environ. Sci. Pollut. Res. 28, 15607-15626. doi:10.1007/s11356-020-12231-8

Srilatha, K., Bhagawan, D., Shiva Kumar, S., and Himabindu, V. (2017). Sustainable Fuel Production by Thermocatalytic Decomposition of Methane - A Review. South Afr. J. Chem. Eng. 24, 156-167. doi:10.1016/j.sajce.2017.10.002

Steinfeld, A. (2002). Solar Hydrogen Production via a Two-step Water-Splitting Thermochemical Cycle Based on $\mathrm{Zn} / \mathrm{ZnO}$ Redox Reactions. Int. J. Hydrogen Energ. 27, 611-619. doi:10.1016/S0360-3199(01)00177-X

Stiegel, G. J., and Ramezan, M. (2006). Hydrogen from Coal Gasification: An Economical Pathway to a Sustainable Energy Future. Int. J. Coal Geology. 65, 173-190. doi:10.1016/j.coal.2005.05.002

Suelves, I., Lázaro, M. J., Moliner, R., Echegoyen, Y., and Palacios, J. M. (2006). Characterization of NiAl and NiCuAl Catalysts Prepared by Different Methods for Hydrogen Production by Thermo Catalytic Decomposition of Methane. Catal. Today 116, 271-280. doi:10.1016/j.cattod.2006.05.071

Suelves, I., Lázaro, M., Moliner, R., Corbella, B., and Palacios, J. (2005). Hydrogen Production by Thermo Catalytic Decomposition of Methane on Ni-Based Catalysts: Influence of Operating Conditions on Catalyst Deactivation and Carbon Characteristics. Int. J. Hydrogen Energ. 30, 1555-1567. doi:10.1016/ j.ijhydene.2004.10.006

Suelves, I., Pinilla, J. L., Lázaro, M. J., Moliner, R., and Palacios, J. M. (2009). Effects of Reaction Conditions on Hydrogen Production and Carbon Nanofiber Properties Generated by Methane Decomposition in a Fixed Bed Reactor Using a NiCuAl Catalyst. J. Power Sourc. 192, 35-42. doi:10.1016/j.jpowsour.2008.11.096

Swain, G., Sultana, S., Moma, J., and Parida, K. (2018). Fabrication of Hierarchical Two-Dimensional MoS2 Nanoflowers Decorated upon Cubic CaIn2S4 Microflowers: Facile Approach to Construct Novel Metal-free P-N Heterojunction Semiconductors with Superior Charge Separation Efficiency. Inorg. Chem. 57, 10059-10071. doi:10.1021/acs.inorgchem.8b01221

Syed Muhammad, A. F. a., Awad, A., Saidur, R., Masiran, N., Salam, A., and Abdullah, B. (2018). Recent Advances in Cleaner Hydrogen Productions via Thermo-Catalytic Decomposition of Methane: Admixture with Hydrocarbon. Int. J. Hydrogen Energ. 43, 18713-18734. doi:10.1016/ j.ijhydene.2018.08.091

Tanaka, H., Kaino, R., Nakagawa, Y., and Tomishige, K. (2010). Comparative Study of $\mathrm{Rh} / \mathrm{MgO}$ Modified with Fe, Co or Ni for the Catalytic Partial Oxidation of Methane at Short Contact Time. Part II: Catalytic Performance and Bed Temperature Profile. Appl. Catal. A: Gen. 378, 187-194. doi:10.1016/j.apcata.2010.02.018

Tao, J., Hou, L., Yan, B., Chen, G., Li, W., Chen, H., et al. (2020). Hydrogen Production via Aqueous-phase Reforming of Ethylene Glycol over a NickelIron Alloy Catalyst: Effect of Cobalt Addition. Energy Fuels 34, 1153-1161. doi:10.1021/acs.energyfuels.9b02149

Timmerberg, S., Kaltschmitt, M., and Finkbeiner, M. (2020). Hydrogen and Hydrogen-Derived Fuels through Methane Decomposition of Natural Gas GHG Emissions and Costs. Energy Convers. Manag. X 7, 100043. doi:10.1016/ j.ecmx.2020.100043

Tomishige, K., Asadullah, M., and Kunimori, K. (2004). Syngas Production by Biomass Gasification Using $\mathrm{Rh} / \mathrm{CeO} 2 / \mathrm{SiO} 2$ Catalysts and Fluidized Bed Reactor. Catal. Today 89, 389-403. doi:10.1016/j.cattod.2004.01.002

Valenzuela, M. B., Jones, C. W., and Agrawal, P. K. (2006). Batch Aqueous-phase Reforming of Woody Biomass. Energy Fuels 20, 1744-1752. doi:10.1021/ ef060113p

Van Dillen, A. J., Terörde, R. J. A. M., Lensveld, D. J., Geus, J. W., and De Jong, K. P. (2003). Synthesis of Supported Catalysts by Impregnation and Drying Using Aqueous Chelated Metal Complexes. J. Catal. 34. doi:10.1016/S0021-9517(02) 00130-610.1002/chin.200336195

Vasiliades, M. A., Damaskinos, C. M., Kyprianou, K. K., Kollia, M., and Efstathiou, A. M. (2020). The Effect of Pt on the Carbon Pathways in the Dry Reforming of Methane over Ni-Pt/Ce0.8Pr0.2O2- $\delta$ Catalyst. Catal. Today 355, 788-803. doi:10.1016/j.cattod.2019.04.022

Villacampa, J. I., Royo, C., Romeo, E., Montoya, J. A., Del Angel, P., and Monzón, A. (2003). Catalytic Decomposition of Methane over Ni-Al2O3 Coprecipitated
Catalysts Reaction and Regeneration Studies. Appl. Catal. A. Gen. 252 (2), 363-383. doi:10.1016/S0926-860X(03)00492-7

Vispute, T. P., and Huber, G. W. (2009). Production of Hydrogen, Alkanes and Polyols by Aqueous Phase Processing of wood-derived Pyrolysis Oils. Green. Chem. 11, 1433. doi:10.1039/b912522c

Vita, A., Cristiano, G., Italiano, C., Pino, L., and Specchia, S. (2015). Syngas Production by Methane Oxy-Steam Reforming on $\mathrm{Me} / \mathrm{CeO} 2(\mathrm{Me}=\mathrm{Rh}, \mathrm{Pt}, \mathrm{Ni})$ Catalyst Lined on Cordierite Monoliths. Appl. Catal. B: Environ. 162, 551-563. doi:10.1016/j.apcatb.2014.07.028

Vogt, C., Kranenborg, J., Monai, M., and Weckhuysen, B. M. (2020). Structure Sensitivity in Steam and Dry Methane Reforming over Nickel: Activity and Carbon Formation. ACS Catal. 10, 1428-1438. doi:10.1021/ acscatal.9b04193

Wang, F., Jiang, Y., Lawes, D. J., Ball, G. E., Zhou, C., Liu, Z., et al. (2015). Analysis of the Promoted Activity and Molecular Mechanism of Hydrogen Production over Fine Au-Pt Alloyed TiO2 Photocatalysts. ACS Catal. 5, 3924-3931. doi:10.1021/acscatal.5b00623

Wang, H., and Baker, R. T. K. (2004). Decomposition of Methane over a $\mathrm{Ni}-\mathrm{Cu}-\mathrm{MgO}$ Catalyst to Produce Hydrogen and Carbon Nanofibers. J. Phys. Chem. B 108, 20273-20277. doi:10.1021/jp040496x

Wang, Q., Cheng, X., Sun, Y., Sun, Z., Wang, D., Chen, G., et al. (2021). A Synergetic Effect between Photogenerated Carriers and Photothermally Enhanced Electrochemical Urea-Assisted Hydrogen Generation on the NiNiO/Nickel Foam Catalyst. Mater. Adv. 2, 2104-2111. doi:10.1039/ dlma00038a

Wang, S., Lu, A., and Zhong, C.-J. (2021). Hydrogen Production from Water Electrolysis: Role of Catalysts. Nano Convergence 8. doi:10.1186/s40580-02100254-x

Wang, Y., Yao, L., Wang, S., Mao, D., and Hu, C. (2018). Low-temperature Catalytic CO2 Dry Reforming of Methane on Ni-Based Catalysts: A Review. Fuel Process. Tech. 169, 199-206. doi:10.1016/j.fuproc.2017.10.007

Weger, L., Abánades, A., and Butler, T. (2017). Methane Cracking as a Bridge Technology to the Hydrogen Economy. Int. J. Hydrogen Energ. 42, 720-731. doi:10.1016/j.ijhydene.2016.11.029

Widjaya, E. R., Chen, G., Bowtell, L., and Hills, C. (2018). Gasification of Nonwoody Biomass: A Literature Review. Renew. Sustain. Energ. Rev. 89, 184-193. doi:10.1016/j.rser.2018.03.023

Williams, A., Pourkashanian, M., Jones, J. M., Skorupska, N., Williams, A., Pourkashanian, M., et al. (2018). Properties of Coal. Combustion and Gasification of Coal, 21-54. doi:10.1201/9781315139746-2

Wysocka, I., Hupka, J., and Rogala, A. (2019). Catalytic Activity of Nickel and Ruthenium-Nickel Catalysts Supported on $\mathrm{SiO} 2, \mathrm{ZrO} 2, \mathrm{Al} 2 \mathrm{O} 3$, and MgAl2O4 in a Dry Reforming Process. Catalysts 9, 540. doi:10.3390/ catal9060540

Xiao, Y., and Varma, A. (2018). Bio-Oil Upgrading Using Methane: A Mechanistic Study of Reactions of Model Compound Guaiacol over Pt-Bi Bimetallic Catalysts. ACS Sustain. Chem. Eng. 6, 17368-17375. doi:10.1021/ acssuschemeng. 8 b04925

Yang, L., Hua, X., Su, J., Luo, W., Chen, S., and Cheng, G. (2015). Highly Efficient Hydrogen Generation from Formic Acid-Sodium Formate over Monodisperse AgPd Nanoparticles at Room Temperature. Appl. Catal. B: Environ. 168-169, 423-428. doi:10.1016/j.apcatb.2015.01.003

Yang, Z., Cao, J.-P., Ren, X.-Y., Zhao, X.-Y., Liu, S.-N., Guo, Z.-X., et al. (2019). Preparation of Hierarchical HZSM-5 Based Sulfated Zirconium Solid Acid Catalyst for Catalytic Upgrading of Pyrolysis Vapors from lignite Pyrolysis. Fuel 237, 1079-1085. doi:10.1016/j.fuel.2018.10.049

Ye, R.-P., Ding, J., Gong, W., Argyle, M. D., Zhong, Q., Wang, Y., et al. (2019). CO2 Hydrogenation to High-Value Products via Heterogeneous Catalysis. Nat. Commun. 10. doi:10.1038/s41467-019-13638-9

Yeheskel, J., and Epstein, M. (2011). Thermolysis of Methane in a Solar Reactor for Mass-Production of Hydrogen and Carbon Nano-Materials. Carbon 49, 4695-4703. doi:10.1016/j.carbon.2011.06.071

Yoshida, K., Begum, N., Ito, S.-i., and Tomishige, K. (2009). Oxidative Steam Reforming of Methane over Ni/a-Al2O3 Modified with Trace noble Metals. Appl. Catal. A: Gen. 358, 186-192. doi:10.1016/j.apcata.2009.02.025

Zhang, G., Liu, J., Xu, Y., and Sun, Y. (2019). Ordered Mesoporous Ni/SilicaCarbon as an Efficient and Stable Catalyst for $\mathrm{CO} 2$ Reforming of 
Methane. Int. J. Hydrogen Energ. 44, 4809-4820. doi:10.1016/ j.ijhydene.2019.01.017

Zhang, L., Wen, X., Kong, T., Zhang, L., Gao, L., Miao, L., et al. (2019). Preparation and Mechanism Research of Ni-Co Supported Catalyst on Hydrogen Production from Coal Pyrolysis. Sci. Rep. 9. doi:10.1038/s41598-019-44271-7

Zhang, T., and Amiridis, M. D. (1998). Hydrogen Production via the Direct Cracking of Methane over Silica-Supported Nickel Catalysts. Appl. Catal. A. Gen. 167 (2), 161-172. doi:10.1016/S0926-860X(97)00143-9

Zhang, Y., and Smith, K. J. (2004). Carbon Formation Thresholds and Catalyst Deactivation during CH4Decomposition on Supported Co and Ni Catalysts. Catal. Lett. 95, 7-12. doi:10.1023/B:CATL.0000023714.69741.1d

Zhou, L., Enakonda, L. R., Saih, Y., Loptain, S., Gary, D., Del-Gallo, P., et al. (2016). Catalytic Methane Decomposition over Fe-Al2O3. ChemSusChem 9, 1243-1248. doi:10.1002/cssc.201600310

Zhu, J., Peng, X., Yao, L., Shen, J., Tong, D., and Hu, C. (2011). The Promoting Effect of $\mathrm{La}, \mathrm{Mg}$, Co and $\mathrm{Zn}$ on the Activity and Stability of Ni/SiO2 Catalyst for CO2 Reforming of Methane. Int. J. Hydrogen Energ. 36, 7094-7104. doi:10.1016/j.ijhydene.2011.02.133
Conflict of Interest: The authors declare that the research was conducted in the absence of any commercial or financial relationships that could be construed as a potential conflict of interest.

Publisher's Note: All claims expressed in this article are solely those of the authors and do not necessarily represent those of their affiliated organizations, or those of the publisher, the editors and the reviewers. Any product that may be evaluated in this article, or claim that may be made by its manufacturer, is not guaranteed or endorsed by the publisher.

Copyright (c) 2021 Naikoo, Arshad, Hassan, Tabook, Pedram, Mustaqeem, Tabassum, Ahmed and Rezakazemi. This is an open-access article distributed under the terms of the Creative Commons Attribution License (CC BY). The use, distribution or reproduction in other forums is permitted, provided the original author(s) and the copyright owner(s) are credited and that the original publication in this journal is cited, in accordance with accepted academic practice. No use, distribution or reproduction is permitted which does not comply with these terms. 